NBER WORKING PAPER SERIES

DO COLLEGE-PREP PROGRAMS IMPROVE LONG-TERM OUTCOMES?

\author{
C. Kirabo Jackson \\ Working Paper 17859 \\ http://www.nber.org/papers/w17859 \\ NATIONAL BUREAU OF ECONOMIC RESEARCH \\ 1050 Massachusetts Avenue \\ Cambridge, MA 02138 \\ February 2012
}

This paper includes material circulated in, and replaces the unpublished NBER working paper \#15722 titled "The Effects of an Incentive-Based High-School Intervention on College Outcomes." The author is grateful for helpful comments and suggestions from Dave Deming, David Figlio and Karl Scholz. All errors are my own. This research was made possible through data provided by the University of Texas at Dallas Education Research Center. The conclusions of this research do not necessarily reflect the opinions or official position of the Texas Education Agency, the Texas Higher Education Coordinating Board, or the State of Texas. The views expressed herein are those of the author and do not necessarily reflect the views of the National Bureau of Economic Research.

NBER working papers are circulated for discussion and comment purposes. They have not been peerreviewed or been subject to the review by the NBER Board of Directors that accompanies official NBER publications.

(C) 2012 by C. Kirabo Jackson. All rights reserved. Short sections of text, not to exceed two paragraphs, may be quoted without explicit permission provided that full credit, including $(\subset$ notice, is given to the source. 
Do College-Prep Programs Improve Long-Term Outcomes?

C. Kirabo Jackson

NBER Working Paper No. 17859

February 2012, Revised September 2012

JEL No. H0,I20,J01

\begin{abstract}
This paper presents an analysis of the longer-run effects of a college-preparatory program implemented in inner-city schools that provided teacher training in addition to payments to eleventh- and twelfthgrade students and their teachers for passing scores on Advanced Placement (AP) exams. Affected students passed more AP exams, were more likely to remain in college beyond their first and second years, and earned higher wages. Effects are particularly pronounced for Hispanic students who experienced a 2.5-percentage-point increase in college degree attainment and an 11-percent increase in earnings. While the study is based on non-experimental variation, the results are robust across a variety of specifications, and most plausible sources of bias are ruled out. The results provide credible evidence that implementing high-quality college-preparatory programs in existing urban schools can improve the long-run educational and labor market outcomes of disadvantaged youth.

C. Kirabo Jackson

Northwestern University

School of Education and Social Policy

2040 Sheridan Road

Evanston, IL 60208

and NBER

kirabo-jackson@northwestern.edu
\end{abstract}




\title{
Do College-Prep Programs Improve Long-Term Outcomes? ${ }^{1}$
}

\author{
C. Kirabo Jackson \\ Northwestern University, IPR, and NBER \\ kirabo-jackson@northwestern.edu
}

This paper presents an analysis of the longer-run effects of a college-preparatory program implemented in inner-city schools that provided teacher training in addition to payments to eleventh- and twelfth- grade students and their teachers for passing scores on Advanced Placement (AP) exams. Affected students passed more AP exams, were more likely to remain in college beyond their first and second years, and earned higher wages. Effects are particularly pronounced for Hispanic students who experienced a 2.5-percentage-point increase in college degree attainment and an 11-percent increase in earnings. While the study is based on non-experimental variation, the results are robust across a variety of specifications, and most plausible sources of bias are ruled out. The results provide credible evidence that implementing high-quality college-preparatory programs in existing urban schools can improve the long-run educational and labor market outcomes of disadvantaged youth.

The economic returns to education have been rising in the United States. In 1979, college-educated adults earned seventy-five percent more than high school graduates, while by 2003, college-educated adults earned two-hundred and thirty percent more than high school graduates (Rouse and Barrow 2006). At the same time, college enrollment is much lower among ethnic-minority high school graduates and among students from low-income families. ${ }^{2}$ As such, these increasing returns have important implications for earnings differences across groups and for intergenerational income mobility in the United States (Turner 2004; Acemoglu and Autor 2010). Motivated by these facts, federal and state governments make significant expenditures on programs aimed at increasing college preparation among disadvantaged populations. ${ }^{3}$ Because students often self-select into such programs, rigorous evaluations are scarce and there are none investigating the effects of college prep-programs on long-run outcomes.

\footnotetext{
${ }^{1}$ This paper includes material circulated in, and replaces the unpublished NBER working paper \#15722 titled "The Effects of an Incentive-Based High-School Intervention on College Outcomes." The author is grateful for helpful comments and suggestions from Dave Deming, David Figlio and Karl Scholz. All errors are my own. This research was made possible through data provided by the University of Texas at Dallas Education Research Center. The conclusions of this research do not necessarily reflect the opinions or official position of the Texas Education Agency, the Texas Higher Education Coordinating Board, or the State of Texas.

${ }^{2}$ Approximately 70 percent of white high school graduates or GED holders between the ages of 25 and 29 enrolled in some college program. The corresponding figures are roughly 60 and 50 percent for blacks and Hispanics, respectively (CPS 2010). Roughly eighty percent of the high school graduates from the top income quartile attend some college compared to under sixty percent of those from the lowest income quartile (Ellwood and Kane 2000).

${ }^{3}$ In 2011, the federal government spent over $\$ 650$ million to promote college-preparation programs for low-income students such as Upward Bound and Gear UP (U.S. Department of Education). Additionally, several states have pushed to expand Advanced Placement and International Baccalaureate programs (Lerner \& Brand, 2008).
} 
This paper aims to fill this void in the literature by analyzing the long-run educational and labor market effects of the Advanced Placement Incentive Program (APIP). The APIP is a high school intervention that includes cash incentives for both teachers and students for passing scores earned on AP exams, teacher training, curricular oversight, and test-prep sessions. The APIP was first adopted in 1996. As such, the first cohorts of affected students are now old enough to have completed their education and be in the labor market. This affords the opportunity to analyze both the long-run educational effects and the labor market outcomes of a college-prep program. While there are existing studies of college-prep program on educational attainment, the ability to rigorously analyze effects on wages makes this study unique. ${ }^{4}$

There are few existing studies on the effects of college-prep programs that use experimental or quasi-experimental research designs, and the results are mixed. Seftor, Mamun, and Schirm (2009) conducted a randomized evaluation of Upward Bound, an intensive collegeprep program for ninth- through twelfth-grade students that includes additional instruction, tutoring, and counseling during the school year, and intensive instruction during the summer. The authors found no overall effect on postsecondary enrollment or completion. However, Cahlan (2008) raises serious questions about these findings because the comparison group may have also received college-prep programming, there was attrition bias, and the sample was weighted heavily to one school with improper implementation. Another study is Jackson (2010) that examined the short-run effects of the APIP and found that the program improves SAT performance and college matriculation. I am aware of no other rigorous studies on college-prep programs, and none that look at long-run labor market outcomes. ${ }^{5}$

The APIP, like most college-preparatory programs such as Upward Bound and GEAR UP, includes academic instruction, tutoring, and counseling. What distinguishes the APIP from other programs is that it also uses cash incentives for both students and teachers to induce greater participation in AP programs, increase teacher encouragement for students to take AP courses, and increase student and teacher effort in AP courses and exams. On the student side, theory

\footnotetext{
${ }^{4}$ Recent findings indicate that students, who disproportionately attend urban schools, have improved educational outcomes when given the opportunity to attend better schools (Deming et al. 2011; Abdulkadiroğlu et al. 2011; Booker et al. 2011; Dobbie \& Fryer 2011; Jackson 2010). However, it has proven difficult to reduce educational disparities by improving the existing schools to which most disadvantaged students are consigned (Murnane 2008).

${ }^{5}$ Kemple and Willner (2008) conduct a randomized evaluation of career academies, which focus on vocational skills through work internships and career-related experiences in addition to academics. They found no effect on educational attainment, but positive effects on labor market outcomes. Because career academies are oriented toward career-relevant skills, these important findings do not speak to the effects of college-preparation programs.
} 
predicts these cash incentives should lead to increased AP participation and effort, if students are myopic, reduce time studying because of the need to work, or face social pressures not to study. On the teacher side, cash incentives should increase AP participation and instruction quality if teachers reduce class sizes, or reduce time spent working with AP students on other activities. As such, the use of cash rewards may make this program particularly likely to succeed. ${ }^{6}$

Using K-12 education data linked to college records (both in Texas and outside of Texas) and unemployment insurance records in Texas in 2010, I investigate how the APIP, which was administered to high-school juniors and seniors, affected their (1) college attendance, (2) sophomore-year college persistence, (3) college completion, and (4) labor market earnings. Because the APIP was not implemented in all interested high schools at once, there is variation in the timing of APIP adoption within the sample of interested schools. This allows for a quasiexperimental difference-in-difference strategy- comparing the change in outcomes between observationally similar students from the same high school before and after APIP adoption to the change in outcomes across cohorts from other high schools that did not adopt the APIP over the same time period. Because the APIP is not a randomized experiment, I am careful to present several tests to demonstrate that the results are not driven by (a) selective migration to treated schools, (b) changes in other school inputs, or (d) changes in school leadership. However, there is evidence of pre-existing trends for some outcomes. I take the conservative approach of only emphasizing those results that are robust to controlling for pre-existing trends.

Consistent with Jackson (2010), there are robust positive effects on AP exam passing. I find suggestive evidence of positive effects on college-going that are only marginally statistically significant after accounting for pre-existing trends. In entirely new findings, there are sizable positive and robust treatment effects on persisting in college beyond freshman year across all specifications. While there is little evidence of an effect on earning a college degree on average, there are robust positive treatment effects on wages across all specifications. Conservative estimates suggest a benefit-cost ratio greater than 10. Consistent with a causal relationship, (a)

\footnotetext{
${ }^{6}$ For incentive-based interventions, such as the APIP, some psychologists argue that external rewards can supplant intrinsic motivation, such that performance may be worse after incentives are removed than if they had never been introduced. This notion is discussed in (Deci and Ryan 1985) and has been popularized in (Kohn 1999). For a balanced meta-analysis of this literature, see (Cameron and Pierce 1994). Based on actual field studies (as opposed to lab studies), Angrist and Lavy (2009) find that student incentives improve outcomes for girls, and Lavy (2009) and Figlio and Kenny (2007) find that teacher incentives are associated with contemporaneous improvements in achievement for all students. According to Angrist, Lang, and Oreopoulos (2009), cash rewards in conjunction with additional supports for academic achievement among college students lead to higher GPAs for female students.
} 
improvements coincide with the timing of APIP adoption, (b) effects are strongest for students most likely to be affected, (c) students at treated schools who were unlikely to be treated experienced no effects, (d) schools with higher treatment intensity experienced larger effects, and (e) outcomes that should not have been affected by the APIP were unrelated to adoption. Across different specifications and outcomes, the results reveal sizable robust benefits for Hispanic students, who experience about a 2.5-percentage point increase in college degree attainment and an 11-percent increase in earnings.

The long-run effects were most significant in schools with established AP programs before APIP adoption and in schools with high-powered incentives. This suggests that increased supply of AP courses was not the driving mechanism, and that increased teacher and student effort associated with the incentives are important aspects of the program's success.

These findings indicate that college-prep programs that both maintain high standards and increase participation in rigorous courses can improve college readiness and long-run educational and labor market outcomes. The results suggest that incentive-based programs that include resources to turn effort into achievement may have lasting positive effects, even after rewards are no longer provided. These findings also contribute to the debate on early versus late interventions (Cunha and Heckman 2007), because they show that an inexpensive program targeted to high school students is effective at increasing educational attainment and earnings. Finally, the results demonstrate that high-quality college-preparatory programs can improve the long-run economic well-being of disadvantaged students consigned to inner-city schools.

The remainder of this paper is structured as follows. Section II describes the APIP program, followed by the presentation of data in Section III. Then, Section IV discusses the empirical strategy. Section V presents the results, specification, and robustness tests, and finally Section VI concludes.

\section{Description of the AP Incentive Program}

AP courses are typically taken by students in eleventh and twelfth grades. The courses are intended to be "college level," and most colleges allow successful AP exam takers to use their scores to offset degree requirements. The AP program has 35 courses and examinations across 20 subject areas. The length of a course varies from one to two semesters. The cost per examination is $\$ 82$, and a fee reduction of $\$ 22$ is granted to those students with demonstrated 
financial need. AP exams are administered by the College Board, making teacher cheating unlikely. Exams are scored on a scale of through 5, where 3 and higher are regarded as passing grades. In Texas, AP courses are taught during regular class time and generally substitute for another course in the same subject, an elective course, or a free period. While AP courses count toward a student's high school GPA, they are beyond what is required for high school graduation and substitute for less demanding activities. ${ }^{7}$

The APIP is run by AP Strategies, a nonprofit organization based in Dallas, and is voluntary for schools, teachers, and students. The heart of the program is a set of financial incentives for teachers and students based on AP examination performance. The program also includes teacher training and curricular oversight conducted by the College Board and a curriculum that prepares students for AP courses in earlier grades. The APIP uses "vertical teams" of teachers. At the top of a vertical team is a lead teacher who instructs students and trains other AP teachers. ${ }^{8}$ In addition to the AP courses taught at school, there may be extra time dedicated to AP training. For example, the APIP in Dallas includes special "prep sessions" for students once or twice a year, where up to 800 students gather at a single high school to take seminars from AP teachers as they prepare for their AP exams (Hudgins 2003).

The monetary incentives are intended to encourage participation and to induce effort in AP courses. AP teachers receive between $\$ 100$ and $\$ 500$ for each AP score of 3 or over earned by a high school junior or senior enrolled in their course and can receive discretionary bonuses of up to $\$ 1,000$ based on results. In addition, lead teachers receive an annual salary bonus of $\$ 3,000$ to $\$ 10,000$, and a further $\$ 2,000$ to $\$ 5,000$ bonus opportunity based on results. While the amount paid per passing AP score and the salary supplements are well defined in each school, there is variation across schools in the amounts paid. Overall, the APIP can deliver a considerable increase in compensation for teachers. ${ }^{9}$

Students in eleventh and twelfth grades also receive incentives for performance. The program pays half of each student's examination fees, so that students on free or reduced lunch would pay $\$ 15$ (instead of $\$ 30$ ), while those who are not would pay $\$ 30$ (instead of $\$ 60$ ) per

\footnotetext{
${ }^{7}$ Source: Executive Vice-President of AP Strategies, and counselors at Dallas high schools.

${ }^{8}$ Vertical teams also include teachers whose grades precede those in which AP courses are offered. For example, a vertical team might create a seventh-grade math curriculum designed to prepare students for AP Calculus in twelfth grade. This may be important, given findings by (Jackson \& Bruegmann, 2009) that teachers learn from their peers.

${ }^{9}$ One AP English teacher in Dallas had six students out of 11 score a 3 or higher on the AP examination in 1995, the year before the APIP was adopted. In 2003, when 49 of her 110 students received a 3 or higher, she earned \$11,550 for participating in the program; this was a substantial increase in annual earnings (Mathews, 2004).
} 
exam. Students receive between $\$ 100$ and \$500 for each score of 3 or above in an eligible subject for which they took the course. The amount paid per exam is well defined in each school, but there is variation across schools in the amount paid per passing AP exam. A student who passes several AP exams during junior and senior years can earn several hundred dollars. Because students must attend the AP courses and pass the AP exams to receive the rewards, the incentives are relatively difficult to game and are thus likely to increase student learning.

The total cost of the program ranges from $\$ 100,000$ to $\$ 200,000$ per school per year, depending on the size of the school and its students' propensity to take AP courses. The average cost per student in an AP class ranges from \$100 to \$300. Private donors pay for roughly 70 percent of the total costs, and the district covers the remainder. Districts pay for teacher training and corresponding travel, release time, and some of the supplies and equipment costs. Donors fund the cash rewards to students and teachers, stipends to teachers, bonuses to teachers and administrators for AP performance, and some of the supplies and equipment costs. ${ }^{10}$

As a rule, adoption of the APIP works as follows. First, interested schools approach AP Strategies and are placed on a list. ${ }^{11}$ AP Strategies then tries to match interested schools to a donor. When a private donor approaches AP Strategies, he or she selects which schools to fund from within the list of interested schools. In most cases, the donor wants a specific district. ${ }^{12}$ Once a willing group of schools has been accepted by the donor, preparations are made (such as training and creation of curricula) and the program is implemented the following calendar year. ${ }^{13}$ Approximately two years are required to fully implement the APIP after a school expresses interest. Donors choose the subjects that are rewarded and ultimately determine the size of the financial rewards. While there are differences across schools, most schools reward English, mathematics, and the sciences.

There is variation in the timing of the introduction of the program across schools that I

\footnotetext{
${ }^{10}$ Today, districts can fund their contribution to the APIP using earmarked funds from the statewide AP incentive program and No Child Left Behind. However, in the first few years of the program, such funds were not available.

${ }^{11}$ There are a few exceptions. Schools in Austin were approached by a donor to adopt the APIP in 2007. In addition, five schools in Dallas secured a donor before approaching AP Strategies.

12 For example, the first ten Dallas schools were chosen based on their proximity to AP Strategies; ST Microelectronics is located in the Carrolton-Farmers community and funded this district's schools; the Priddy Foundation specifically requested the Burkburnett and City View schools; anonymous donors specifically requested Amarillo and Pflugerville schools; the Dell Foundation (based in Austin) funds the Austin and Houston programs; and the remaining Dallas schools were funded by the O'Donnell Foundation to complete the funding of Dallas ISD.

${ }^{13}$ The seven schools that adopted the APIP in 2008, however, decided to have the pre-AP preparation portion of the program in place for at least a year before the rewards were provided.
} 
exploit to identify the effect of the program. As illustrated in Figure 1, 58 schools adopted the APIP by 2008 (56 of which were early enough to have college outcomes). Because donor preferences determine the schools that will adopt the program in any given year, among interested schools, donor availability and preferences are the primary reasons for variation in the timing of program implementation. ${ }^{14}$ To quote the Vice-President of AP Strategies, "Many districts are interested in the program but there are no donors. So there is always a shortage of donors.” I argue that the exact timing of program adoption, within the group of willing schools, is orthogonal to changes in potentially confounding school characteristics. I test this assumption empirically in Section VI and show that it is likely valid.

\section{The APIP Schools and the Data}

To show how APIP schools differ from other schools in Texas, I present school-level summary statistics from the National Center for Education Statistics and the Texas Education Agency (TEA) in Table 1. Schools selected for the APIP were different from schools that had not been selected for the APIP. The APIP schools had average enrollments during 2000 through 2005 of 1836 students compared to 751 students for non APIP schools in Texas. During these years, 74 percent of the APIP schools were in large or mid-sized cities compared to under 20 percent for non-APIP schools. During these years, only 25 percent of students at APIP schools were white compared to 53 percent at non-APIP schools, and 10 percent of students had limited English proficiency at APIP schools compared to less than four percent at other schools. Both groups, however, have similar shares of economically disadvantaged students, reflecting the fact that Texas has both urban and rural poor.

The regression data contain individual student records from every public tertiary institution in Texas ${ }^{15}$ between 1995 and 2010, every private institution in Texas between 2003 and 2010, ${ }^{16}$ and most higher education institutions across all of the United States listed in the National Student Clearinghouse between 2008 and 2010 from the Texas Higher Education Coordinating Board. These data are linked with student-level high school and middle school data

\footnotetext{
${ }^{14}$ For example, in 2005, four high schools were chosen by The Michael and Susan Dell Foundation from a list of seven interested Houston schools. The remaining three schools may adopt the program at a later date.

15 Texas has 145 institutions of higher learning. Of the public institutions, there are 35 universities, 50 community colleges, nine health-related institutions, four technical colleges, and three state colleges. On the private side, there are 39 universities, two junior colleges and three heath-related institutions.

${ }^{16}$ Because private school data are only available after 2003, I have run all models using only those cohorts that would have expected high school graduation after 2003, and the main results are largely the same.
} 
(including standardized tenth-grade test scores that all students must take by state law) from the TEA for the years 1994 through $2007 .{ }^{17}$ The standardized test scores are standardized to be mean zero with unit variance for each test administration. For each student, I use the most recent administration of the test (i.e., the year directly preceding expected exposure to the APIP). ${ }^{18}$ These education data are linked to earnings and employment data for the fourth quarter in 2010 from the Texas Workforce Commission (TWC). These labor market data come from unemployment insurance records and provide information on earnings for employed Texas residents. Utilizing earnings data from only the fourth quarter in 2010 has a few benefits. First, using data across the same time period for all workers removes any potentially confounding effect associated with certain workers being employed at different points of the business cycle. Second, using fourth-quarter earnings (as opposed to using annual earnings) allows one to observe workers who graduated in May of 2010 and were employed in the fourth quarter of that year - effectively increasing the sample size for this outcome by about twenty-five percent. The final dataset contains 2010 labor market outcomes, college outcomes, as well as high school and middle school data of all students who were in tenth grade between 1994 and 2007. Using the population of tenth graders allows me to account for attrition that may take place after APIP exposure in eleventh and twelfth grades. ${ }^{19}$

In Table 2, I present the pre- and post-APIP adoption summary statistics for schools that adopted the APIP by 2008 (note: schools adopt the APIP at different times so the pre-adoption years differ across schools). About 22.9 percent of students who were in tenth grade during the pre-adoption years took an AP course while in high school, compared to 30.4 percent in the postadoption period. Similar increases in AP exam-taking were observed, where those in tenth grade during the pre period took 0.097 exams and those in the post period took 0.127 exams during high school. The tenth-grade math and reading scores were below zero for both periods, indicating that APIP schools were low-achieving schools on average. These scores were slightly lower after adoption than before, suggesting possible negative selection into APIP schools.

The average student before adoption was in tenth grade in 1999 compared to 2003 for the post-adoption sample. As such, variables that increase with age, such as college attendance and

\footnotetext{
${ }^{17}$ TAKS (1994-2003) and TASP (2003-2007).

18 The tenth-grade retention rate was approximately seven percent in Texas in 1995; among minorities, this figure was over 10 percent (http://www.tea.state.tx.us/reports/1996cmprpt/04retain.html).

${ }^{19}$ For example, if the APIP caused students to drop out of high school in eleventh grade, then using the population of juniors or senior would yield results that suffer from attrition bias.
} 
earning, are difficult to compare without directly accounting for age (as is done in the regression analysis). However, to allow for a simple comparison, I compute enrollment by the time since expected high school graduation (not shown in the table). About 35, 46, and 53 percent of tenth graders in the pre-treatment cohorts were freshmen in college within one, two, and three years of expected high school graduation, respectively. The tenth graders in post-adoption cohorts were more likely to attend college, such that 41,50 , and 56 percent of tenth-grade students in posttreatment cohorts were freshmen in college within one, two, and three years of expected high school graduation, respectively. ${ }^{20}$ The implied sophomore-year persistence (the share of students who were sophomores divided by the share who were freshmen) is 0.53 and 0.544 for the preand post-adoption cohorts, respectively. ${ }^{21}$ Comparing figures for ever being a freshman to the enrollment figures above reveals that 59, 79, and 89 percent of college attendance occurs within one, two, and three years of expected high school graduation, respectively. Because analyzing college outcomes within four years of expected high school graduation ignores about one tenth of the variation in enrollment (and even more of the variation in college completion), I analyze college outcomes at any point in time and then control for cohort differences directly.

As the outcomes that change are a function of age, because age and treatment status are correlated, a simple treated versus un-treated comparison understates any effects of the APIP. In any case, among the untreated cohorts, 18 percent of high school sophomores eventually earn a college degree compared to about 14 percent of the treated (younger) cohorts. Looking to labor market outcomes, about 49 percent of tenth graders in the untreated cohorts were employed (according to unemployment insurance records) in 2010 and received mean three-month earnings of $\$ 8,029.60$, while about 46 percent of tenth graders in the treated (younger) cohorts were in the labor market receiving mean three-month earnings of $\$ 4,895.20$.

\section{Empirical Strategy}

Before presenting the identification strategy, I discuss some methodological concerns facing this and similar studies and then I present my proposed solutions. Because the APIP affects high school juniors and seniors, it influences the characteristics of students while still in

\footnotetext{
${ }^{20}$ Texas has the second-largest community college system in the US, so many students enroll in two-year colleges.

${ }^{21}$ The sophomore variables are not computed for the 2007 cohort because they would have been freshman in 2010 if they had enrolled directly after expected high school graduation. College graduation variables are computed for cohorts before 2004 because later cohorts are very unlikely to have graduated from a four-year college by 2010 .
} 
high school, so that one must compare students who were similar before exposure to the APIP. As such, I compare the outcomes of students with similar attributes before exposure to APIP from the same high school, and I do not control for potentially endogenous covariates such as SAT scores or high school GPA. ${ }^{22}$ The second methodological issue is how treatment is defined. Because students may enroll at APIP schools in eleventh and twelfth grades to benefit from the program, defining treatment based on actual school enrollment in these grades could be subject to selection bias. To avoid such bias, I use intention-to-treat (ITT) instead of whether a student is actually affected by the APIP. Specifically, I define ITT based on whether a student would be treated if she remained in her tenth-grade high school and were never held back a grade. For example, a student is intended for treatment if she is enrolled at a school in tenth grade in year $t$, and the school will have adopted the APIP by year $t+2$. Using ITT is advantageous because it is not endogenously determined by student selection into APIP schools in eleventh and twelfth grades, or subject to biases due to attrition or retention. ${ }^{23}$ In addition, employing ITT yields a clean policy-relevant estimate of the effect of introducing the APIP to the target population.

IV.1 Identification Strategy: The identification strategy is to compare the difference in outcomes across cohorts of students who attended the same high school before and after APIP adoption to the difference in outcomes between cohorts of students at schools that did not adopt the APIP over the same time period. Comparing students from the same high school addresses the concern that students at schools that adopt the APIP may differ from students who attend schools that do not adopt the APIP. By comparing cohorts, as opposed to students within cohorts, I address the concern that certain types of students tend to take AP courses and exams for unobserved reasons while others do not. Furthermore, by comparing the outcomes of students with the same tenth grade test scores and demographics, I address the concern that the incoming preparation of students may have changed in APIP schools after adoption of the program. Finally, this approach helps to account for potentially confounding statewide policies. ${ }^{24}$

This strategy relies on the assumption that the difference in outcomes across cohorts for comparison schools is the same, in expectation, as the difference in outcomes across cohorts that

\footnotetext{
${ }^{22}$ Many studies mistakenly control for endogenous variables to isolate the causal effect of AP exams.

${ }^{23}$ The downside of this measure is that it will not capture the full effect of the treatment on the treated since (1) students who leave APIP schools after tenth grade will not be treated but will be intended for treatment, (2) students who enter APIP schools after tenth grade will be treated but will not be intended for treatment, and (3) retained students, who should have graduated before APIP adoption, will be treated but will not be intended for treatment.

${ }^{24}$ For a description of such policies, see Appendix Note 2.
} 
adopting schools would have experienced if they had not adopted the APIP. For this to be plausible, the comparison schools must be similar to APIP-adopting schools. To ensure that this is the case, I restrict the estimation sample to those schools that adopted the APIP by 2008, using the change in outcomes for other APIP schools that did not yet have the opportunity to implement the program as the counterfactual change in outcomes. This sample restriction has two important benefits: (1) because APIP-willing schools are observationally similar, they likely share common time shocks; and (2) because APIP-willing schools are similarly motivated and interested, restricting the sample in this way avoids comparing schools with motivated principals to schools with unmotivated principals who have no interest in the program. ${ }^{25}$

Because I do not compare schools that adopt the APIP to those that do not, using a within-school estimation strategy controls for school selection on unobserved time-invariant characteristics, such as time-constant school enthusiasm or motivation. Identification relies on the assumption that the timing of APIP implementation is exogenous to other within-school changes. Since the timing of actual adoption relies on idiosyncratic donor preferences and availability, this assumption is plausible. However, because donor choices are not random, I cannot entirely rule out that the timing of adoption is uncorrelated with changes in school characteristics. As such, to assuage concern that timing of adoption may be endogenous, I identify those schools with which donors had prior relationships and verify that all the main results are robust to excluding these schools. $^{26}$ In addition, in Section V, I show that improvements only take place after APIP adoption; the timing of adoption is unrelated to other school changes or the timing of the arrival of a new principal; improvements are only experienced in AP-related outcomes and not other outcomes; and improvements are experienced almost entirely by students who were ex-ante likely to take AP courses and to be "treated." While none of these tests are dispositive individually, the weight of evidence indicates that the assumption of exogenous timing of adoption is probably valid.

This within-school cohort-based comparison is implemented by estimating the following equation by Ordinary Least Squares (OLS).

\footnotetext{
${ }^{25}$ Some schools adopted the APIP after 2007 and are therefore never treated in-sample for the purposes of analyzing college outcomes, but serve as comparison schools. The results are similar (albeit less precise) when using only schools that adopt the APIP in-sample, so the findings are not driven by the particular choice of comparison schools. ${ }^{26}$ For a detailed discussion, see Appendix Note 1.
} 


$$
Y_{\text {ich }}=\beta_{1} X_{i}+\beta_{2} A_{i}+\sum_{k=1} \mu_{k} I_{I T T \text { year }=k}+\theta_{h}+\theta_{c}+\varepsilon_{\text {ich }}
$$

In [1], $Y_{\text {ich }}$ is the outcome of student $i$ in tenth-grade cohort $c$, from high school $h . X_{i}$ is a matrix of student demographic characteristics, such as race, gender, and free-lunch status in tenth grade. $A_{1}$ is a vector of student achievement scores from tenth grade. To control for differences in student attributes across high schools, changes in performance over time, and differences in outcomes across cohorts, I include high school-fixed effects $\theta_{h}$, and cohort fixed effects $\theta_{c}$. The variable of interest $I_{\text {ITT year }=k}$ is an indicator variable denoting the ITT year, so that $\mu_{1}$ is the effect of the APIP in its first intention-to-treat year, and $\mu_{k}$ is the effect of the APIP in its $\mathrm{k}^{\text {th }}$ intention-to-treat year. Standard errors are adjusted for clustering at the school level.

A simple before/after comparison likely understates the full effect of the APIP because the first affected cohort is exposed to the two-year program for only one year. As such, the first cohort to receive the "full treatment" is the second cohort ( $\left.\operatorname{ITT}_{\text {year }}=2\right)$. Because there are likely learning-by-doing effects, and it may take time for the AP program to mature, outcomes may continue to improve beyond the second cohort. As such, to identify the dynamic APIP effect, I use binary variables denoting the first, second, third, and fourth plus ITT years. For example, the first ITT cohort for a school has ITT year=1, and the third ITT cohort for a school has ITT year=3. In this regression, the ITT year denotes how long the APIP had been in place when the student was expected to graduate from high school. ${ }^{27}$

\section{Results}

\section{Effects on Short-Run Advanced Placement Outcomes}

Table 3 presents the regression results for the main outcomes. The top panel reports the coefficient on the simple before/after adoption indicator, and the lower panel reports the coefficients on the first, second, third, and fourth plus intention-to-treat years. For AP course taking (column 1), the simple before/after comparison yields a statistically insignificant increase of 0.061. The dynamic effect on the lower panel shows a statistically significant increase of 0.165 (about a 21-percent increase) by year three. The null hypothesis that all the dynamic APIP

\footnotetext{
${ }^{27}$ For example, if the APIP were adopted in school $h$ in the 2002-03 school year, the tenth-grade cohort for the school year 2000-01 would be coded as ITT year=1, while the tenth-grade cohort for the school year 2002-03 would be coded as ITT year $=3$.
} 
effects are zero is rejected at the five-percent level, which is suggestive of some positive effect on AP course taking Columns 2 and 3 show the effects on AP exams taken and AP exams passed. Unlike for AP course taking, the adoption indicator and all the ITT treatment year dummies are statistically significant. By the fourth year, the APIP is associated with a 0.098 increase (about a 100-percent increase) in the number of AP exams taken, and a 0.043 increase (about a 45-percent increase) in the number of AP exams passed. The increases are primarily in the English and science AP exams (Appendix Table 4). The APIP may affect unmeasured outcomes (such as aspirations or self-confidence) that could in turn impact college outcomes but may not be reflected in these AP outcomes. As such, while these AP effects are important, they may not measure all of the APIP effects and should therefore not be used to scale the effects on college outcomes as if it were a "first stage."

To present visual evidence of an APIP effect on AP outcomes, Figure 2 shows the results of estimating a flexible version of equation [1], where I estimate effects for both pre-adoption years and post-adoption years. For each outcome, I plot the estimated coefficients of ITT years 4 through 5 (the first adoption cohort is year 1 and the first "fully treated" cohort is year 2). There are visible increases in AP course taking and AP exam passing after APIP adoption. Close inspection reveals that there may have been an increase in AP course taking for those $10^{\text {th }}$ graders in the cohort before the APIP was adopted in $11^{\text {th }}$ grade. This could have happened for two legitimate reasons; first, teachers received AP training and may have promoted the AP program in the year directly preceding the implementation of the incentives; second, because the results are based on intention to treat, any student who repeats $11^{\text {th }}$ or $12^{\text {th }}$ grade will receive the treatment but be coded as being in a pre-treatment cohort (the combined grade 11 and 12 retention rate in 2000 for Black and Hispanic students was over 15 percent so that this is a real possibility). In any case, I take the conservative view and interpret this increase as evidence of a small increase in AP course taking prior to APIP adoption that must be controlled for. To show the effects are robust to any pre-existing trends, the lower panel of Table 3 shows the coefficients on the estimated coefficients of ITT years 1 through 4 from a regression that includes school specific linear time trends. ${ }^{28}$ The dynamic treatment effects are very similar — indicative of a

\footnotetext{
${ }^{28}$ That is, I estimate equation [2] below, where all variables are defined as before, Year $_{c}$ is the cohort's tenth-grade year, and $\tau_{h}$ is a school-specific linear trend for school $h$. In this model, the APIP effect is the average change in outcomes across treated schools estimated relative to each school's own intercept and own time trend. Note that the model includes an indicator for each of the post treatment years (i.e. ITT years 1 through 14) so that I do not use
} 
real APIP effect on AP course taking, exam taking and exam passing.

\section{Effects on College Attendance}

Column 4 of Table 3 presents the APIP effect on being a freshman- at any 2-year or fouryear college The before/after comparison shows that the APIP increases college attendance by about 4.2 percentage points on average. Appendix Table A2 shows that this is driven by both two-year and four-year college attendance and is not driven by reduced college-going from out of state. The dynamic effects suggest that the effect of the APIP increases over time. Figure 3 shows the plot of the dynamic treatment effect before and after APIP adoption. While collegegoing is greater for those post treatment cohort, this appears to be an artifact of an upward trend in the outcome before APIP adoption. The lower panel of Table 3 that accounts for trending supports this conclusion. The estimated effect on ever being a freshman is about half as large in models that account for trending, and the effects are no longer statistically significant at the 5 percent level. However, the fact that the effects for the ITT cohorts 2 and 3 are statistically significant at the 10 percent level relative to trend, is suggestive evidence of a college-going effect. However, a conservative interpretation is that there is no effect on college-going.

\section{Effects on Outcomes at College}

Most college attrition occurs in the first year, and thus, persistence through the first year is a key predictor of college success. As such, the APIP could have important effects if it increased college persistence even if it had little to no effect on college going. Column 5 of Table 3 presents regression results for sophomore-year college enrollment among those with expected high school graduation by 2006. APIP adoption is associated with a 4.3-percentage point increase in ever being a college sophomore on average, and a 6.6-percentage point increase for the fourth ITT cohort and beyond. This represents a 20-percent increase four years after adoption. Column 6 shows results on freshman year GPA among college enrollees for illustrative

variation after adoption to identify the trend. However, I only report estimated coefficients on ITT years 1 through 4 to be consistent with previous specifications.

[2] $\quad Y_{\text {ich }}=\beta_{1} X_{i}+\beta_{2} A_{i}+\sum_{k=1} \mu_{k} I_{\text {ITT year }=k}+\theta_{h}+\tau_{h}$ Year $_{c}+\theta_{c}+\varepsilon_{\text {ich }}$ 
purposes. ${ }^{29}$ As one can see, affected cohorts also had 0.066 higher freshman year GPAs. Appendix Table A9 shows that, they were also two percentage points more likely to be enrolled in college as a junior, and earned 7.49 more college credits on average. Despite evidence of increased persistence and better college outcomes, there is little evidence of increase college completion on average. In columns 6, none of the point estimates is statistically significant at the five percent level, indicating that the APIP has no effect on college graduation on average.

To present visual evidence of a real APIP effect on college persistence, in Figure 4, I present the dynamic treatment effect on ever being a sophomore and freshman year GPA. There is an evident improvement in sophomore year enrollment after APIP adoption, specifically after the second ITT cohort (that received the treatment for the full two years). These increases are coincident with increases in freshman year GPA after APIP adoption. While there is clearly an APIP effect, there is some visible evidence of a slight upward trend before adoption. As such, the lower panel of Table 3 presents models that include school-specific linear time trends. While the point estimates are about 25 percent smaller for the $4^{\text {th }}$ ITT cohort, there is a clear statistically significant increase in sophomore year attendance relative to any pre-existing trending. Also, one cannot reject the null hypothesis that the effects on sophomore year persistence in the same with and without trends at the ten percent level of significance - evidence of a real APIP effect on college persistence and educational attainment that is not driven by underlying trends in the data.

\section{Effects on Long-Run Labor Market Outcomes}

Given that the goal of all college-preparatory programs is to improve the economic wellbeing of affected students, the most important outcome is earnings. Figure 5 presents the kernel density plot of log earnings for the treated and untreated cohorts after removing school-fixed effects and cohort-fixed effects. In these models observations with no earning are assigned a value of zero. However, all the results are similar if one only looks at earnings among those with positive earnings or if one imputes earnings for missing observations based on observable characteristics. Moreover, as highlighted in Lemieux (2010), treatment effects on such a measure reflect important changes on both the likelihood of employment and earnings conditional on employment. However, to allow one to tell these margins apart, I also present effects on the

\footnotetext{
${ }^{29}$ I present the GPA results as supportive evidence. Note that the results are similar looking at GPA among college enrollees, or using imputed GPA for students who do not attend college based on their observed covariates.
} 
likelihood of being employed. As one can see, the distribution of residual log earnings is higher among those in the treated cohorts than those in the untreated cohorts. Also, the shift occurs primarily in the middle of the earnings distribution.

In Figure 6, I present the dynamic treatment effect on the likelihood of having any earnings in 2010 and the log of earnings. While the likelihood of being employed in 2010 is somewhat higher after APIP adoption than before by the $4^{\text {th }}$ ITT cohort, the effect on working is effectively zero. I take this as an indication that there was no real labor force participation effect of the APIP. In contrast, despite little change in the likelihood of working on average, there is a clear increase in earnings associated with APIP adoption, and there is little visual evidence of trending for this outcome. Consistent with this visual evidence, the results in column 8 of Table 3 show a positive APIP effect on earnings that is robust to the inclusion of linear time trends. Specifically, adoption is associated with 2.7-percent higher earnings on average, and this effect is largest for the second post-adoption cohort, which experienced a 3.8-percent increase in earnings. In section V.2, I show that these wage effects are more pronounced for certain groups than others. Note that because the APIP had a small positive effect on having any earnings data, imputing wages for missing values based on observable covariates, using only workers with positive earnings, or imputing zeros for missing wages, all yield similar results.

\section{V.1 Effects on Likely AP Course Takers}

The results thus far indicate that the APIP increases AP participation, sophomore-year persistence, and earnings. Given that the APIP aims to improve outcomes by improving the quality of AP instruction, increasing student and teacher effort in AP courses, and increasing participation in the AP program, one would expect larger effects for students who are likely to take AP courses. To test this, I estimate the propensity to take AP courses based on observable student covariates and their interactions using the untreated observations, and then I use this model to predict ex-ante propensities for all students in the data. Next, I estimate the main treatment effects on the sample of students with estimated propensities above 0.66. If the improved outcomes work through improvement in the AP program (as hypothesized), then the treatment effects should be larger among these students.

I present the simple before/after DID estimates in the top row of Table 4. Consistent with the proposed mechanisms, the treatment effects are much larger for this group of students. 
Specifically, within this sample, the APIP increases the number of AP exams passed by 0.17, and increases enrolling in college as a sophomore by 9.2 percentage points. Unlike with the full sample, these likely AP takers are 1.8 percentage points more likely to graduate from college with any degree. Finally, these students earn 5.7-percent higher wages. In sum, among students at APIP-adopting schools who are most likely to be affected by the APIP, program adoption is associated with markedly improved educational outcomes and labor market outcomes. This suggests a true causal effect that works through the hypothesized mechanisms.

\section{V.2 Addressing Threats to Validity}

Because the results are not based on a randomized controlled trial, there is no "silver bullet” identification strategy. As such, while I am careful to compare cohorts within the same school to avoid self-selection within a cohort and selection across schools, I limit the estimation sample to only the APIP schools that are of similar motivation, I show that the main results are robust to pre-existing trending in the data, and I document larger effects for likely AP takers, a few endogeneity concerns remain. I outline these concerns and present empirical tests to address each concern in this section. While none of these tests is dispositive in isolation, all these tests together present a compelling case that the estimated APIP effects can be interpreted causally.

(a) The timing of adoption may be associated with the arrival of a new principal. Related to the previous point, one may worry that the timing of adoption is related to the arrival of a new principal who makes a variety of new changes other than the APIP, which would confound the estimated APIP effects. To test for this, I predict having a new high school principal as a function of whether the program will be adopted in three years, two years, or one year, or was adopted in the same year. These models include school-fixed effects and year-fixed effects only. In each of these four regressions (shown in Appendix Table A3), the $p$-values associated with the null hypothesis of no systematic relationship are larger than 0.2. I also estimate a specification similar to equation (1) and find no effect on subsequent principal turnover (Appendix Table A4). This is consistent with assertions that timing of adoption is idiosyncratic, and suggests that adoption is likely exogenous to changes in schools over time.

(b) The benefits of the APIP could be driven by general improvements in schools. One may wonder whether the benefits of the APIP are driven by other school-wide changes (such as better inputs or change in teaching philosophy) that would operate through some channel other than the 
AP program. Table 4 shows that the effects are larger for those students with high likelihoods of taking AP courses. If the overall improved effects are truly caused by the AP program, then there should be very small effects for students who are unlikely to take AP courses. If other schoolwide policies could have impacted long-run outcomes, then one should see APIP adoption effects on these students. Estimated effects for this sample of students, who are unlikely to take AP courses, are presented in the second panel of Table 4. As one can see, one cannot reject the null hypothesis of no adoption effect for those with estimated likelihood below 0.33 at the 10 percent level. This suggests that AP students receive the benefits of the APIP, and the estimated effects are not driven by other confounding changes at schools.

As an additional test, I investigate the APIP effect on school-level outcomes that should not be affected by the APIP as a falsification exercise. Because students who take AP courses are not likely to be on the margin of graduating from high school, there should be no effect on high school graduation. Appendix Table A4 shows that APIP adoption is unrelated to graduating from high school. Similarly, Appendix Table A4 shows that the APIP has no effect on teacher turnover, total school expenditures, the number of teachers, teacher experience, or average class size. ${ }^{30}$ By the fourth year, the only outcome for which there is a statistically significant effect is the number of AP teachers, which is consistent with an expansion of the AP program. For all other outcomes, including total school spending, there is no significant effect, suggesting that the effects are not due to general improvements in schools.

(c) High-ability, motivated students may self-select into APIP schools after adoption. Another concern is that these improvements are the result of motivated students self-selecting into secondary schools that adopt the APIP. ${ }^{31}$ If positive selection were driving the results, then the APIP should be associated with characteristics that lead to better outcomes. To test for this, I predict the main outcomes as a function of observable student characteristics before APIP

\footnotetext{
${ }^{30}$ While there is little evidence of this, in principle, some of the effects could have been driven by changes in the composition of teachers, as documented in (Jackson, 2009).

${ }^{31}$ This is a potential problem because there is the possibility of selective migration. While none of the treated districts allow students from outside the district to enroll, the large urban school districts in Texas (Dallas, Houston, and Austin) practice intradistrict choice, where students have the option to attend their neighborhood schools or another school in the district (including magnet and charter schools), subject to space limitations at the receiving school. Because Houston and Austin schools did not adopt the APIP until 2007, this only poses a problem for Dallas schools. To further ensure that selective migration does not drive the results, I estimate the APIP effect without Dallas schools, and the results are similar. It is also worth noting that under No Child Left Behind, students attending a Title I school designated as "in need of improvement" have the right to attend a higher-performing school in the district. However, in most districts, the APIP schools are the lower-performing schools.
} 
adoption. ${ }^{32}$ I then regress the predicted outcomes on the adoption indicator variables, school effects, and year effects. If there were selection on observable characteristics that affect outcomes, adoption would affect these predicted outcomes. For all the predicted outcomes, the point estimates are close to zero, and the $p$-values associated with the hypothesis that the adoption year variables are correlated with the predicted outcomes exceed 0.2 (Table 5). ${ }^{33}$ This suggests that there is no selection in observed dimensions that are associated with the outcomes.

(d) There may be selection to APIP schools in unobserved dimensions. To ensure the results are not driven by selective migration on unobservable characteristics, I estimate equation [1] while including indicator variables for each middle-school-by-high-school combination. Students who self-select into high school because of the APIP will come from middle schools that are not the natural feeder middle schools for the APIP schools (if they were, there would be no need to select). I can avoid comparing the outcomes of students who do self-select to APIP schools from non-feeder middle schools to those of students who attended the natural feeder middle schools and did not self-select by making inferences based on the within-middle-school-by-high-school variation. That is, I only compare the outcomes of students who attended the same middle school and the same high school, so that variation in treatment cannot arise from differences in students' potentially endogenous choice of school. Furthermore, I remove all students who attended middle schools that sent fewer than 300 students to any given APIP high school during the sample period. This removes almost all potential for bias from student selection. The results (available upon request) are similar to the main results — indicating no selection. ${ }^{34}$

(e) Increased persistence could be due to changes in timing. Readers may wonder whether the sophomore persistence effects merely reflect that the APIP causes students to enroll in school sooner and therefore be sophomores sooner. To assess this, I analyze sophomore enrollment within one, two, three, and four years of expected high school graduation in Appendix Table A6.

\footnotetext{
32 That is, I estimate a regression using the untreated cohort to predict the main outcomes based on all the preeleventh-grade covariates and their interactions and then use this model to create predicted outcomes for all students. For the effect of the APIP on individual covariates see appendix Table A5.

${ }^{33}$ I present effects on individual covariates in Appendix Table A5, which indicate that treated cohorts had lower tenth-grade test scores, were less likely to be from low-income households, and were less likely to be Hispanic. While these differences exist, overall treated students had very similar predicted outcomes as untreated students.

${ }^{34}$ In principle, one could estimate an intention to treat model based on a student's enrollment in middle school. However, estimating such a model in practice becomes complicated because some middle schools feed into multiple high schools, and some high schools draw students from multiple middle schools. Also, this specification would require very large treatment effect among eleventh and twelfth grade students to be detected among eight graders. Furthermore, this would require observing many students five years before high school graduation and would therefore preclude analysis of the first 10 treated schools.
} 
If the effects were due to students enrolling in school sooner rather than later, one would see stronger effects on enrollment close to high school graduation and no effect within longer time horizons. For example, if students attended college within one year of high school graduation rather than three years, one would see effects on "ever a sophomore within one year of high school graduation" but would see no effect on "ever a sophomore within four years of high school graduation." In actuality, the effects grow as one considers longer time horizons, which is exactly what one would see if the effect reflects increased college attendance overall; thus, it is inconsistent with the results being caused by shifting to earlier college entry.

This section shows that the timing of APIP adoption coincides with the timing of improved outcomes; improvements are concentrated among students who should have been affected through the hypothesized mechanisms; there are no impacts on students who are not affected by the hypothesized mechanisms; there are improvements in those outcomes that should be affected by the APIP; there are no improvements in outcomes that should not have been affected by the APIP; the timing of adoption is unrelated to changes in school leadership or changes in other school inputs; and the effects are not driven by pre-existing improvement over time. As such, even though the variation used is imperfect, the weight of the evidence supports a positive causal APIP effect.

\section{V.2 Effects by Ethnicity.}

Klopfenstein (2004) documents large differences in AP participation across ethnic groups both across and within schools (even among students with the same incoming test scores), so that there may be differences in treatment status by ethnicity. As such, I estimate APIP effects on sub-samples of students based on ethnicity. ${ }^{35}$ I report these effects for black, Hispanic, and white students separately in Table 6. Summary statistics by ethnicity are presented in Appendix Table A7. Some notable patterns are evident. All three groups experience sizable increases in sophomore-year college attendance. Specifically, white students experience an 8.9-percentage point increase by the fourth treated cohort, while black and Hispanic students experience 4.7 and 6.2-percentage point increases, respectively. These increases represent about a 10-percent increase for all groups. All groups experience an increase in junior year college attendance and total credits earned. However, Hispanic students experience a 2.6-percentage point increase in

\footnotetext{
${ }^{35}$ I also estimate effects by gender and find little difference.
} 
BA degree receipt, white students experience no increase, and there appears to be a transitory 1.8 percentage point increase for black students.

To assess the degree to which these BA degree effects for black and Hispanic students are driven by pre-existing trends, I plot the dynamic treatment effects on ever being enrolled as a college junior and graduating with a BA degree before and after APIP adoption for Hispanic and black students in Figures 7 and 8, respectively. In both figures there is a discernible increase in outcomes after APIP adoption that is not due to any pre-existing trend - indicative of real positive APIP effects on college graduation for minority students. However, the graduation effects are marginally statistically significant and non-permanent for black students, while they are strongly statistically significant and increasing over time for Hispanic students.

While there appear to be only graduation effects for black and Hispanic students, all groups experience increased earnings (Column 8 of Table 6). To show robustness to trends I present estimates that include linear time trends for each school in column 9. In such models, wages for black students increase by 8.2 percent, those for Hispanic students by 5.1 percent, and those for whites by 8.4 percent either three or four years after APIP adoption.

These increased earnings could be due to improved labor market skills after graduating from high school or may reflect increased earnings due to attending college. If these increased earnings were due to increased college attendance, then one should see relatively large wage effects for Hispanic students (for whom there is a clear increase in BA degree receipt) from the early cohorts (who are old enough to have graduated from college and have some labor market earnings). To test for this, I estimate the wage effect using only the cohort of students who were expected to graduate from high school before 2003 while accounting for pre-existing trends. These results in column 12 are consistent with college degree effects driving the wage effects for Hispanic students. Among the older cohorts that have completed their schooling, wage effects (a 14-percent increase by the third post-adoption cohort) are only observed for Hispanic students who also experience a robust and statistically significant increase in the likelihood of earning a BA degree. The flipside of this result is that improved labor market outcomes for black and white students from the late cohorts cannot be attributed to earning a BA degree, but must be the result of increased skills or the additional schooling (albeit without the degree). These wage increases of roughly 10 percent are similar to those associated with increased math coursework among those who do not attend college documented by Goodman (2009). 


\section{V.3 Evidence of the Mechanisms:}

In this section, I try to shed light on the underlying mechanisms behind the APIP effect.

Are the improvements driven by increased supply of AP courses and sections? It is natural to wonder if the improved outcomes are merely due to an increase in the availability of AP courses and sections. To address this question, I analyze the APIP effect on schools that had above the median number of AP sections before 1996 (schools that had no statistically significant growth in the number of AP sections after adoption) and on those that had below the median number (schools that experienced a statistically significant 150-percent increase in AP sections offered by the fourth adoption year). If the benefits of the APIP were solely due to an increase in the supply of AP sections, one would expect large effects on high-growth schools and small effects on low-growth schools. However, exactly the opposite is true. There are small improvements in college and labor market outcomes for high-growth schools and large improvements for lowgrowth schools (Table 4), indicating that AP course supply does not drive the results.

Are schools/teachers/students motivated by the incentives? One of the key differences between the APIP and other college-prep programs is the use of cash incentives for students and teachers. As such, it is important to determine whether this is one of the driving mechanisms of the APIP's success. If better resource utilization (caused by the incentives) drives the success of the APIP, and effort is proportional to the size of the rewards, schools that paid higher-powered incentives would obtain better outcomes than those that did not. To test this, I compare the adoption effect on high-power schools (paid between \$101 and \$500 per exam) and low-powered schools (paid \$100 per exam) in Table 4. While the effect on AP exam passing is similar across these school types (Jackson 2010), for all college outcomes, the effects are more significant on high-power schools. Looking to labor market outcomes, the results suggest that both low-powered and highpowered schools see the benefits of the APIP. Students from lower-powered schools see increased labor market participation by 3.5 percentage points but no effect on wages, while those from higher-powered schools see increased wages by 5.4 percent. Taken as a whole, these findings suggest that the monetary incentives and the increased effort they induce are an important component of the APIP's successes.

How important are the non incentive aspects of the program? The improved curricula in earlier grades, teacher training, curricular oversight, vertical teams, and college counseling could all be 
partially responsible for the success of the APIP. Because the first cohort is only exposed to the APIP for one year, the first cohort to have the full incentive component of the APIP is the second treatment cohort. As such, if the effects were driven by incentives alone, the effects would be the same in the second year as in all subsequent years. For most outcomes, however, this is not the case, suggesting that learning-by-doing or other components of the APIP, which would take a few years to take effect (such as improvements in earlier grades or changes in norms), are central to the effects. One can test for improvements in earlier grades by examining the incoming tenthgrade test scores. Results in Appendix Table A5 show that incoming scores are slightly lower after adoption than before, suggesting that improvements in incoming academic preparedness is not the driving force of the APIP's success. This demonstrates that learning-by-doing and changes in school culture are the likely explanations for enhanced APIP effects over time.

Did information or peer norms play a role? Even though I do not have data on student information or on peer norms, to speak to these issues somewhat, I did obtain qualitative interview evidence from guidance counselors. Guidance counselors at three different APIP high schools indicate that school-wide campaigns were implemented to increase their students' participation in AP courses after APIP adoption. At two of the three high schools, an additional guidance counselor was hired to improve these schools' ability to identify those students who should be encouraged to take AP courses. At all three schools, the guidance counselors were given explicit instructions to identify those students who should be taking AP courses and to encourage AP participation. A large part of this campaign involved providing information. Guidance counselors and AP teachers promoted the AP program to students who were interested in going to college, citing the scholarships one could earn based on AP scores, the tuition one could save by graduating at an accelerated pace, and the potential increase in high school GPA. Guidance counselors also mentioned a shift in student and teacher attitudes toward AP courses, such that AP courses were no longer considered only for the very brightest students.

The tests above suggest that increased supply of courses is not the driving force behind the AP participation response or improved labor market outcomes. That the effects are more significant among high-incentive schools suggests that providing additional supply and removing barriers to taking AP courses alone would not lead to success, but that increased student and teacher effort is an important component of the program. The fact that the effects grow over time suggests that the program aspects emphasized by guidance counselors-such as information and 
outreach (that schools will have become more proficient at over time)—are also important. The body of evidence indicates that all aspects of the APIP are important and that providing cash incentives to students or teachers alone, providing teacher training alone, or expanding the AP course offerings alone would not have yielded the same results as the full intervention.

\section{Discussion and Conclusions}

Using a carefully selected of group of comparison schools within which APIP adoption is likely exogenous, I find that students who were more likely to persist beyond their freshman year, and those who were most likely to take AP courses were more likely to graduate from a four-year college. Moreover, affected students earned higher wages. Because both young and old cohorts enjoyed wage increases, the wage increases are consistent with both increased skills attained while in high school and college and higher wages associated with increased postsecondary educational attainment. In both cases, the college-preparatory program conferred longrun benefits upon affected students.

The APIP led to larger improvements in educational attainment and earnings for Hispanic students (the group with the lowest baseline college attendance rates) than for white and black students. These findings suggest that, in addition to reducing ethnic gaps within schools, because the program was targeted to inner-city school with low shares of high income and white students, the program also helped to reduce educational and earnings gaps overall. The earnings increases associated with the APIP for Hispanic and black students are large enough to reduce the blackwhite earnings gap by one third and to eliminate the Hispanic-white earnings gap entirely.

Given that I find no evidence of worse outcomes associated with the APIP, these improvements are likely the result of increased exposure to rigorous. Consistent with this interpretation, APIP adoption is associated with increased AP course taking and AP examination taking, and the effects only exist for students who were ex ante likely to take AP courses. The evidence on mechanisms indicates that both the incentive aspects and the non incentive aspects are important. The lack of any documented ill effects of the APIP suggests that many of the hypothesized detrimental effects of using student incentives or teacher performance pay need not pose a large practical problem in a well-designed incentive-based scheme that combines incentives with additional resources to help translate increased effort into results.

The total cost of the program is roughly \$225 per high school junior and senior. Because 
most students are exposed to the program for two years, the average cost per affected student is $\$ 450$. Using the smallest estimated wage increases as an estimate of the benefits, among students exposed to the APIP for two years, the increase in earnings in 2010 was 3.7 percent. For individuals with baseline annual earnings of $\$ 25,000$ per year, this would be an annual increase of $\$ 925$. As such, the benefit-cost ratio for this low level of earnings would be about 2:1 if this was a one-time wage increase. Under the more realistic assumption that the 3.7-percent increase is persistent and affects lifetime earnings, an individual with a starting wage of $\$ 25,000$ would have an approximate present discounted value of lifetime earnings of $\$ 450,000 .^{36}$ This would imply a lifetime benefit of the APIP of $\$ 16,650$ and a benefit-to-cost ratio of 37:1. With higher baseline earnings, this ratio would be even higher.

Because the large increases in AP participation imply that low AP participation may have reflected some sub-optimality such as poor information, sub-optimal peer norms, or barriers to taking AP exams, it is unsurprising that the economic returns to the program are large. The improvements imply that it may be possible to enhance outcomes by improving both students' and teachers' decision-making and increasing access to well-taught rigorous courses.

While recent evidence has demonstrated that moving students out of low-performing schools and into high-performing schools can improve student outcomes, very little evidence has shown that one can improve students' long-run outcomes by adopting a program at their existing schools. Because there has been little credible evidence on the efficacy of college-prep programs despite large public and private expenditure on such programs, the results of this study are encouraging about the potential efficacy of college-preparatory programs at improving the educational outcomes of disadvantaged students who are consigned to inner-city schools.

${ }^{36}$ Assuming a working life of 35 years, wage growth of two percent per year and a discount rate of seven percent. 


\section{Bibliography}

Abdulkadiroğlu, A., J.D. Angrist, S.M. Dynarski, T.J. Kane, and P.A. Pathal. 2011. "Accountability and Flexibility in Public Schools: Evidence from Boston’s Charters and Pilots." Quarterly Journal of Economics 126, no. 2:699-748.

Acemoglu, Daron and David H. Autor. 2010. "Skills, Tasks and Technologies: Implications for Employment and Earnings.” In Orley Ashenfelter and David Card,eds., Handbook of Labor Economics, Elsevier, Vol. 4B, 1043-1171.

Adelman, C. 1999 Answers in the Tool Box: Academic Intensity, Attendance Patterns, and Bachelor's Degree Attainment. Washington, DC: U.S. Department of Education.

Angrist, J., and V. Lavy. 2009. "The Effects of High Stakes High School Achievement Awards: Evidence from a Group-Randomized Trial.” Amercian Economic Review 99:1384-1414.

Angrist, J., D. Lang, and P. Oreopoulos. 2009. "Incentives and Services for College Achievement: Evidence from a Randomized Trial." American Economic Journal: Applied Economics 1, no. 1:136-163.

Booker, K., T.R. Sass, B. Gill, and R. Zimmer. 2011. "The Effect of Charter High Schools on Educational Attainment.” Journal of Labor Economics 29, no. 2:377-415.

Bound, John, Michael F. Lovenheim, and Sarah Turner. 2010. "Why Have College Completion Rates Declined? An Analysis of Changing Student Preparation and Collegiate Resources." American Economic Journal: Applied Economics, 2(3): 129-57.

Cahlan, M. 2008. "A PART Tragedy: The Case of Upward Bound Correcting for Study Error in the Random Assignment 1992-2004 National Evaluation of Upward Bound.” United States Department of Education Report.

Cameron, J., and D.W. Pierce. 1994. "Reinforcement, Reward, and Intrinsic Motivation: A Meta-Analysis." Review of Educational Research 64:363-423.

Cunha, F., and J. Heckman. 2007. “The Technology of Skill Formation.” American Economic Review 97, no. 2:31-47.

Deci, E. L., and R.M. Ryan. 1985. Intrinsic Motivation and Self-Determination in Human Behavior. New York: Plenum.

Deming, D., J. Hastings, T. Kane, and D. Staiger. 2011. "School Choice, School Quality and Academic Achievement.” Unpublished.

Dobbie, W., and R.G. Fryer. 2011. "Living in the Zone: An Analysis of a Bold Social Experiment in Harlem.” American Economic Journal: Applied Economics 3, no. 3:158-187. 
Ellwood, David and Thomas J. Kane, "Who is Getting a College Education: Family Background and the Growing Gaps in Enrollment” in Sheldon Danziger and Jane Waldfogel (eds.) Securing the Future (New York: Russell Sage Foundation, 2000).

Figlio, D. N., and L.W. Kenny. 2007. "Individual Teacher Incentives and Student Performance.” Journal of Public Economics 91, nos. 5-6:901-914.

Flores-Lagunes, Alfonso., and Audrey Light, 2010."Interpreting Degree Effects in the Returns to Education," Journal of Human Resources, University of Wisconsin Press, vol. 45(2).

Goodman, J. 2009. "The Labor of Division: Returns to Compulsory Math Coursework.” Working Paper Harvard University.

Hudgins, K. 2003, May. "Advanced Placement Program Proves It Pays to Study Hard: A Kick Start for College.” Fiscal Notes.

Jackson, C. K. 2010. “A Little Now for a Lot Later: A Look at a Texas Advanced Placement Incentive Program. Journal of Human Resources 45, no. 3.

Jackson, C. K. 2010. "Do Students Benefit From Attending Better Schools?: Evidence from Rule-based Student Assignments in Trinidad and Tobago.” Economic Journal.

Jackson, C. K. 2009. "Student Demographics, Teacher Sorting, and Teacher Qualty: Evidence from the End of School Desegregation.” Journal of Labor Economics 27, no. 2:213-256.

Jackson, C. K. 2010. "The Effects of an Incentive-Based High-School Intervention on College Outcomes.” NBER Working Paper 15722.

Jackson, C. K., and E. Bruegmann. 2009. "Teaching Students and Teaching Each Other: The Importance of Peer Learning for Teachers.” American Economic Journal: Applied Economics 1, no. 4:85-108.

Kemple, J. J., and C.J. Willner. 2008. Career Academies Long-Term Impacts on Labor Market Outcomes, Educational Attainment, and Transitions to Adulthood. MDRC.

Klopfenstein, K. 2004. "The Advanced Placement Expansion of the 1990s: How Did Traditionally Underserved Students Fare?” Education Policy Analysis Archives 12, no. 68.

Kohn, A. 1999. Punished by Rewards: The Trouble with Gold Stars, Incentive Plans, A's, Praise, and Other Bribes. Bridgewater, NJ: Replica Books.

Lavy, V. 2009. "Performance Pay and Teachers’ Effort, Productivity and Grading Ethics.” American Economic Review. 
Lemieux, Thomas. 2011. "Minimum Wages and the Joint Distribution Employment and Wages" Working Paper.

Lerner, J. B., and B. Brand. 2008. "Review of State Policies Supporting Advanced Placement, International Baccalaureate, and Dual Credit Programs.” Baccalaureate and Dual Credit Programs.

Mathews, J. 2004. "Paying Teachers and Students for Good Scores.” The Washington Post, August 10.

Mervis, J. 2011. "Navy Paying Students to Succeed on AP Tests.” Education Next, October 27.

Murnane, R. J. 2008. “Educating Urban Children.” NBER Working Paper 13791.

Neal, D., and W. Johnson. 1996. "The Role of Premarket Factors in Black-White Wage Differences.” The Journal of Political Economy 104, no. 5:869-895.

Rouse, Cecilia and Lisa Barrow. 2006. "U.S. Elementary and Secondary Schools: Equalizing Opportunity or Replicating the Status Quo?” The Future of Children 16(2): 99-123.

Seftor, N. S., A. Mamun, and A. Schirm. 2009. "The Impacts of Regular Upward Bound on Postsecondary Outcomes 7-9 Years After Scheduled High School Graduation.” Mathematica Report.

Turner, Sarah. 2004. "Going to College and Finishing College: Explaining Different Educational Outcomes.” In College Choices: The Economics of Where to Go, When to Go, and How to Pay for It, edited by Caroline M. Hoxby, 13-61. Chicago: University of Chicago Press. 


\section{Figures and Tables}

Figure 1: Number of Schools Adopting APIP: By Year

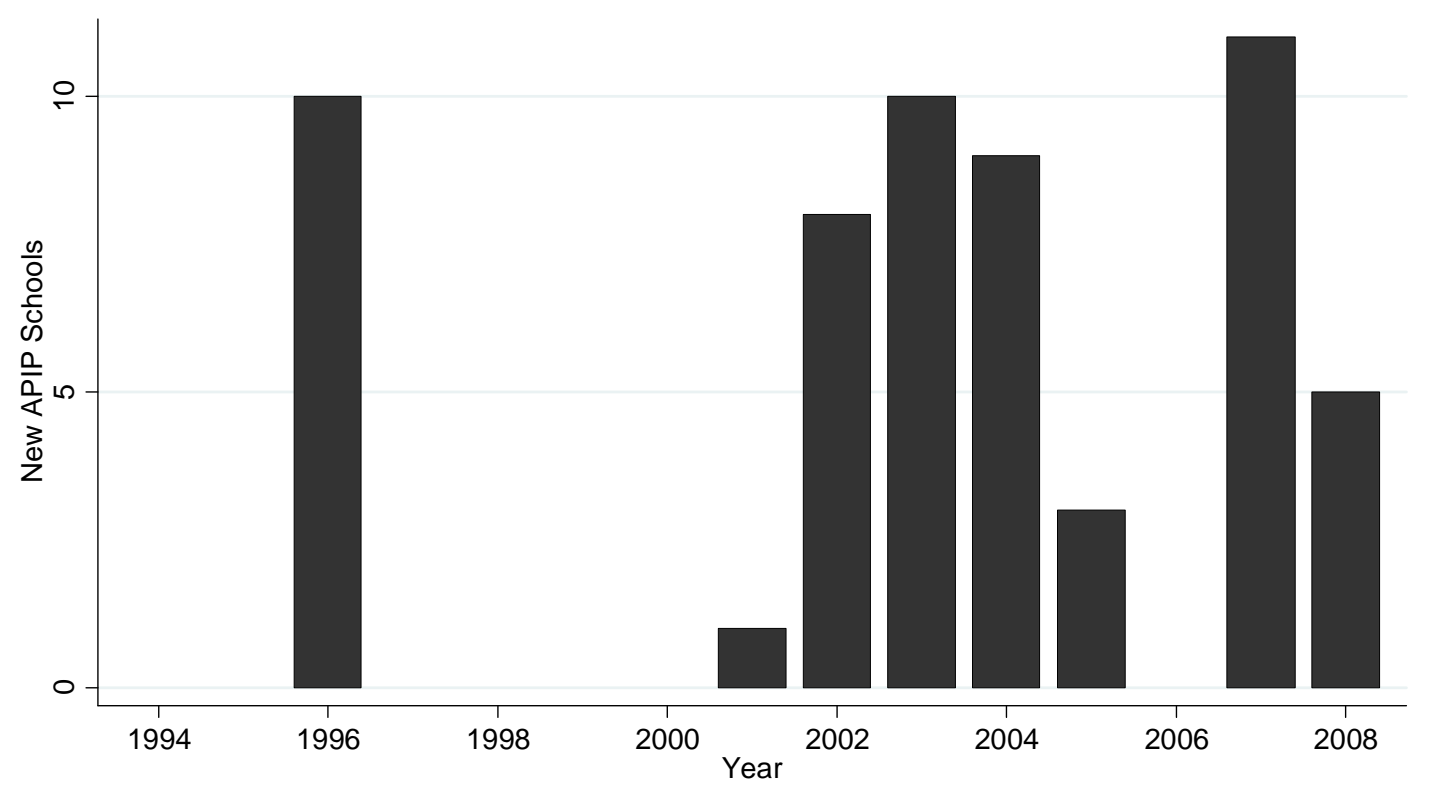

Figure 2: Effect on AP Outcomes

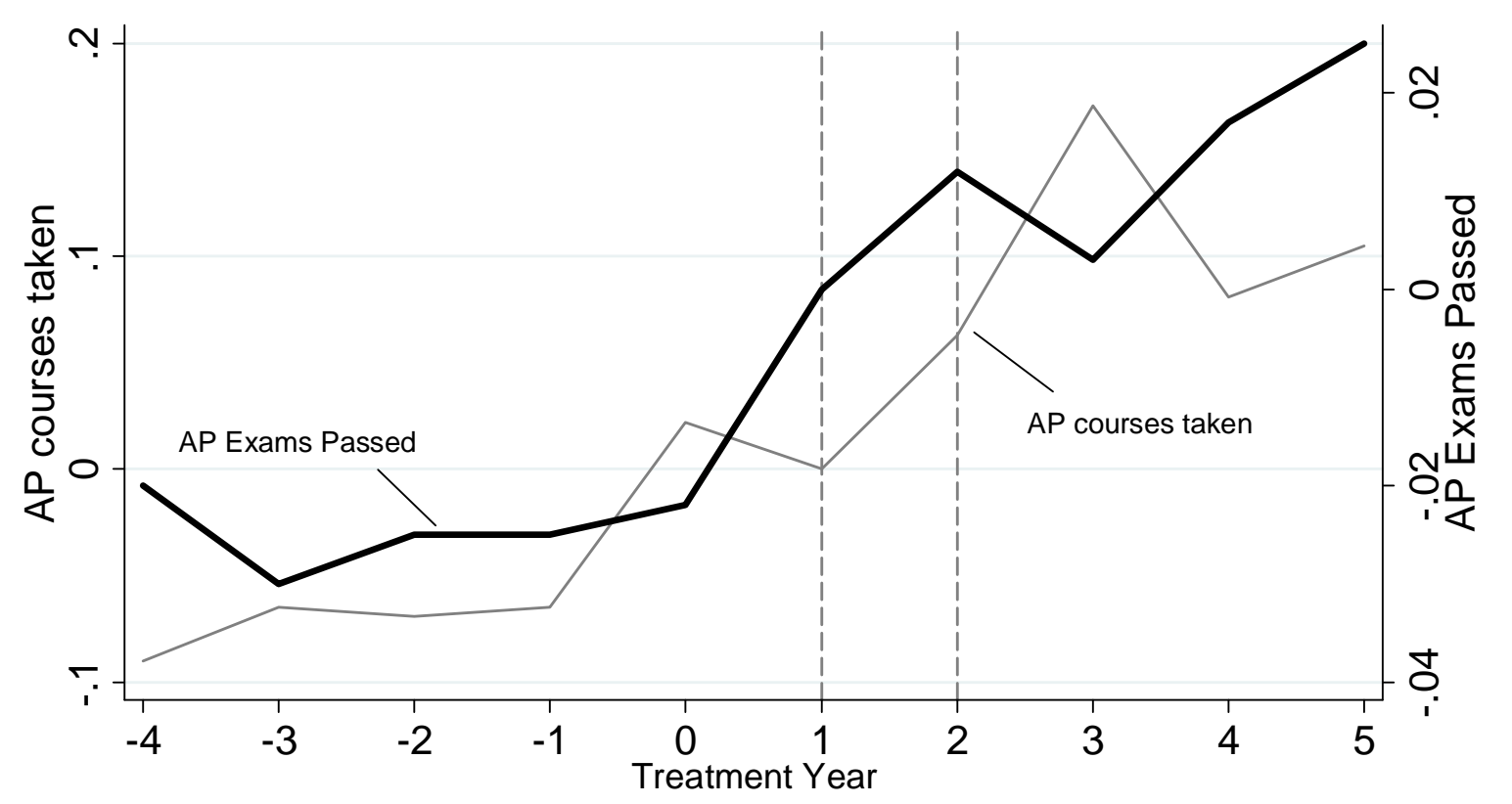

This figure shows the results of estimating a flexible version of equation [1], where I estimate effects for both preadoption years and post-adoption years. For each outcome, I plot the estimated coefficients of ITT years -4 through 5 (the first adoption cohort is year 1 and the first "fully treated" cohort is year 2). 
Figure 3: Effect on College Going (Evidence of pre-Existing Trend in College Going)

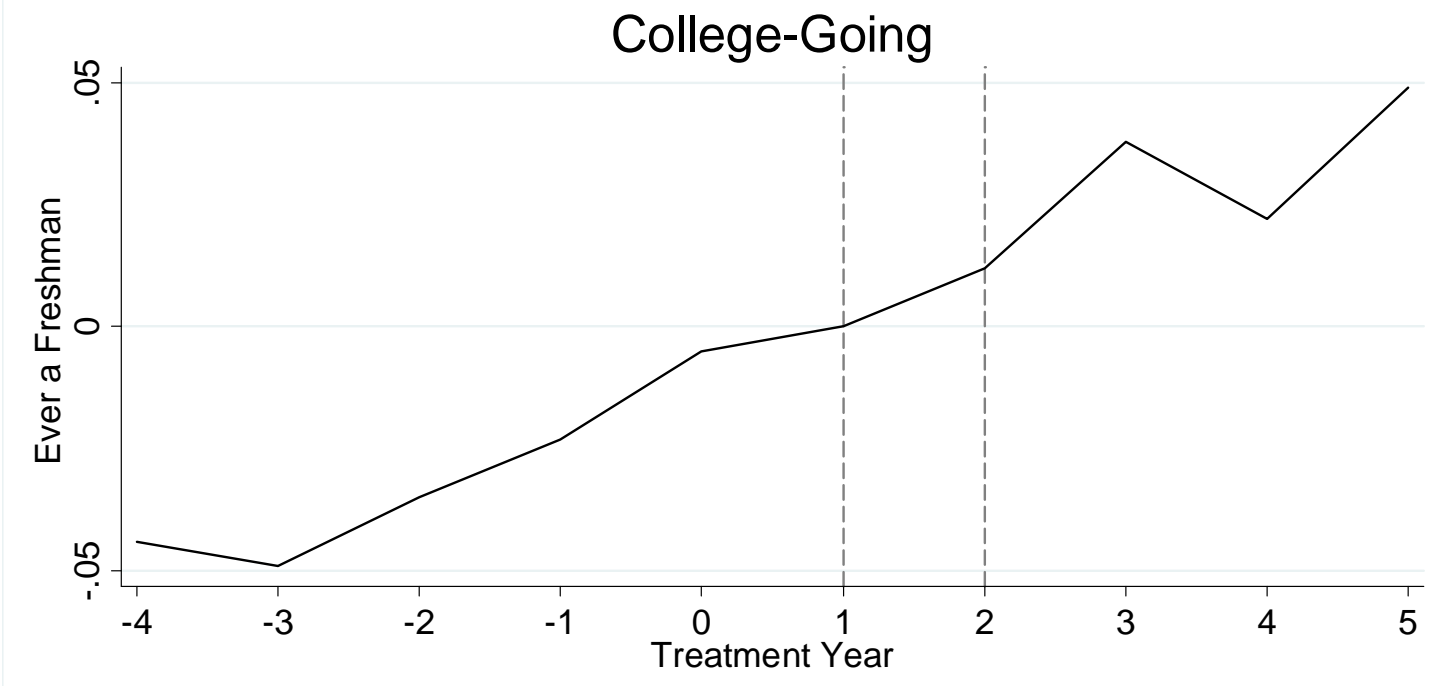

This figure shows the results of estimating a flexible version of equation [1], where I estimate effects for both preadoption years and post-adoption years. For each outcome, I plot the estimated coefficients of ITT years -4 through 5 (the first adoption cohort is year 1 and the first "fully treated" cohort is year 2).

Figure 4: Effect on College Outcomes

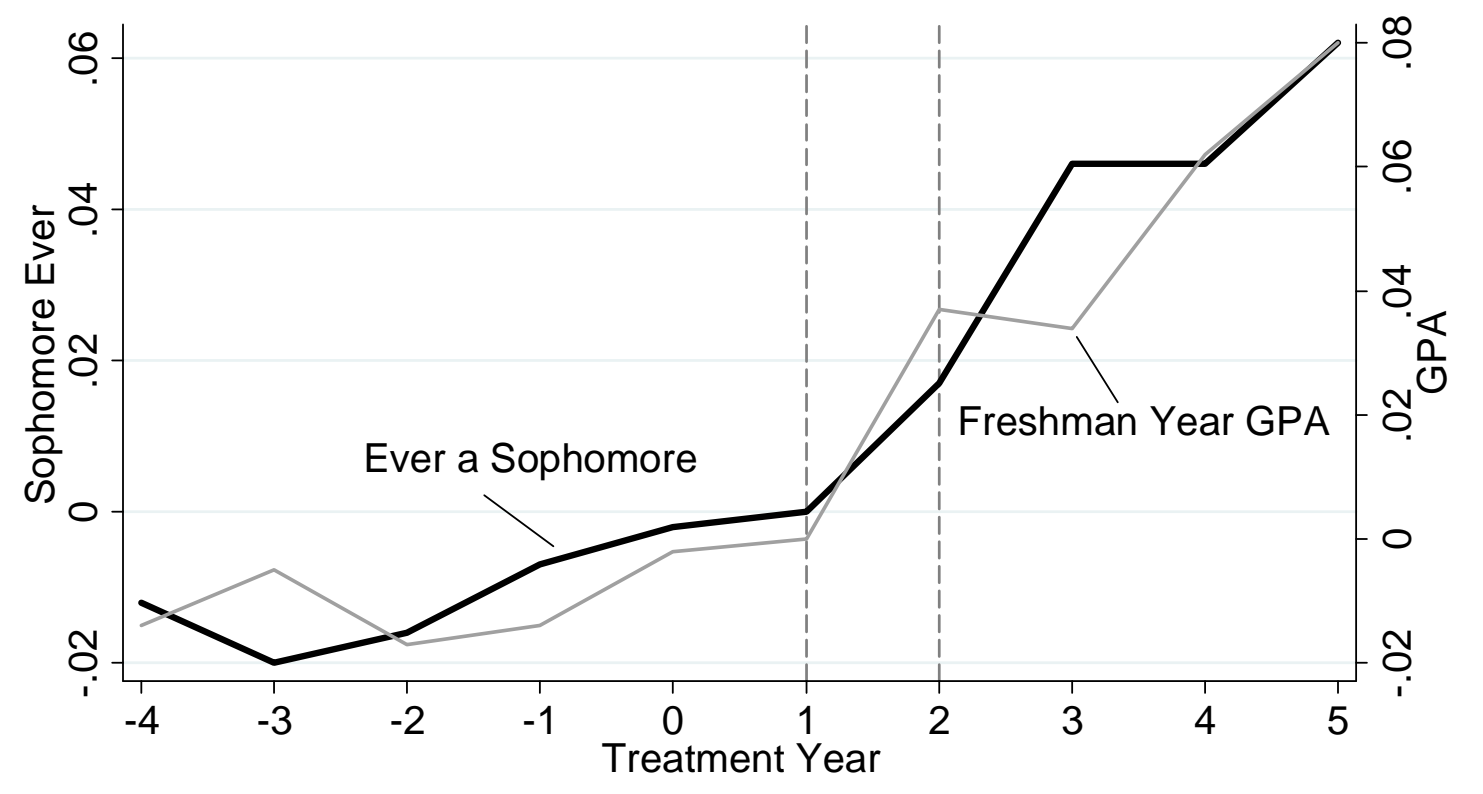

This figure shows the results of estimating a flexible version of equation [1], where I estimate effects for both preadoption years and post-adoption years. For each outcome, I plot the estimated coefficients of ITT years -4 through 5 (the first adoption cohort is year 1 and the first "fully treated" cohort is year 2). 
Figure 5: Wages for Treated and Untreated Cohorts

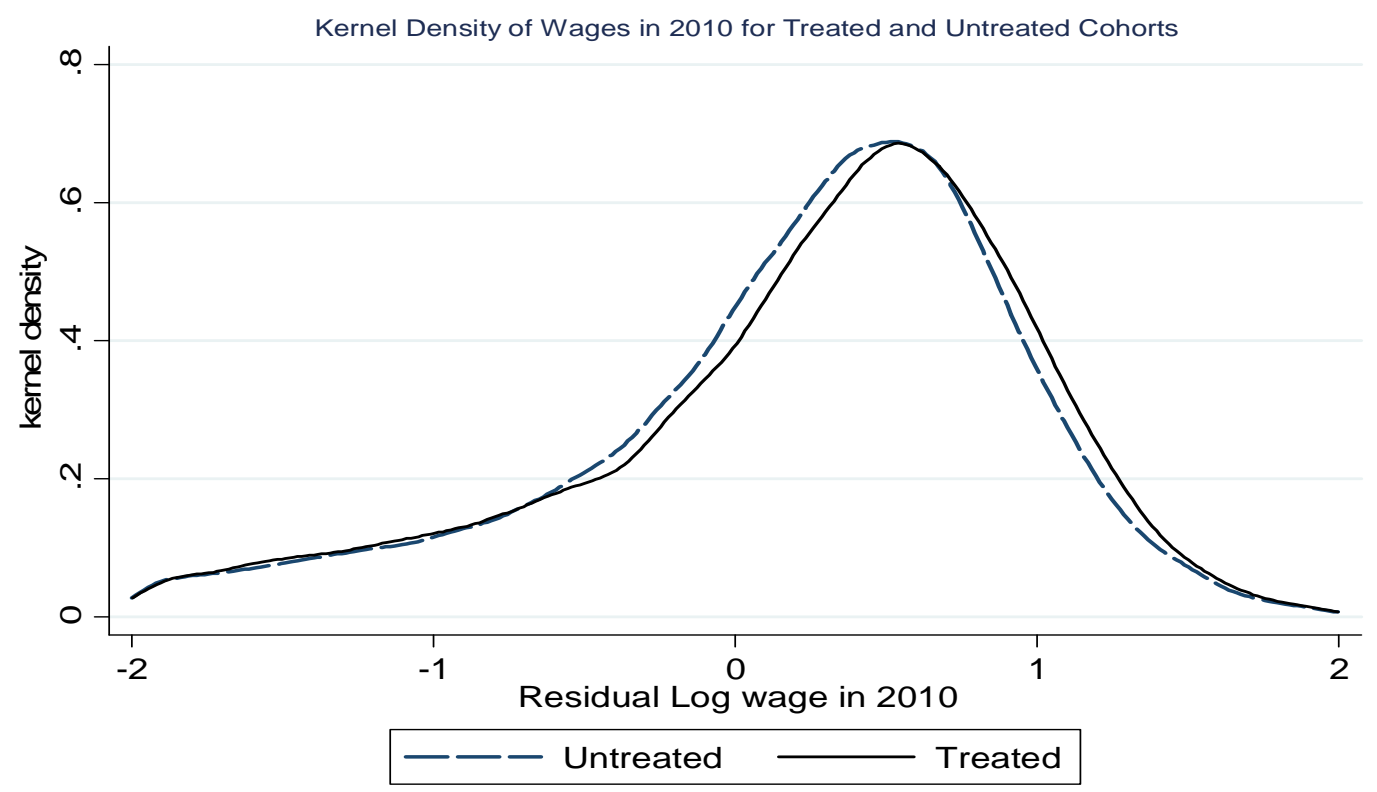

This figure presents the kernel density plot of earnings for the treated and untreated cohorts after removing schoolfixed effects and cohort-fixed effects.

Figure 6: Effect on Labor Market Outcomes

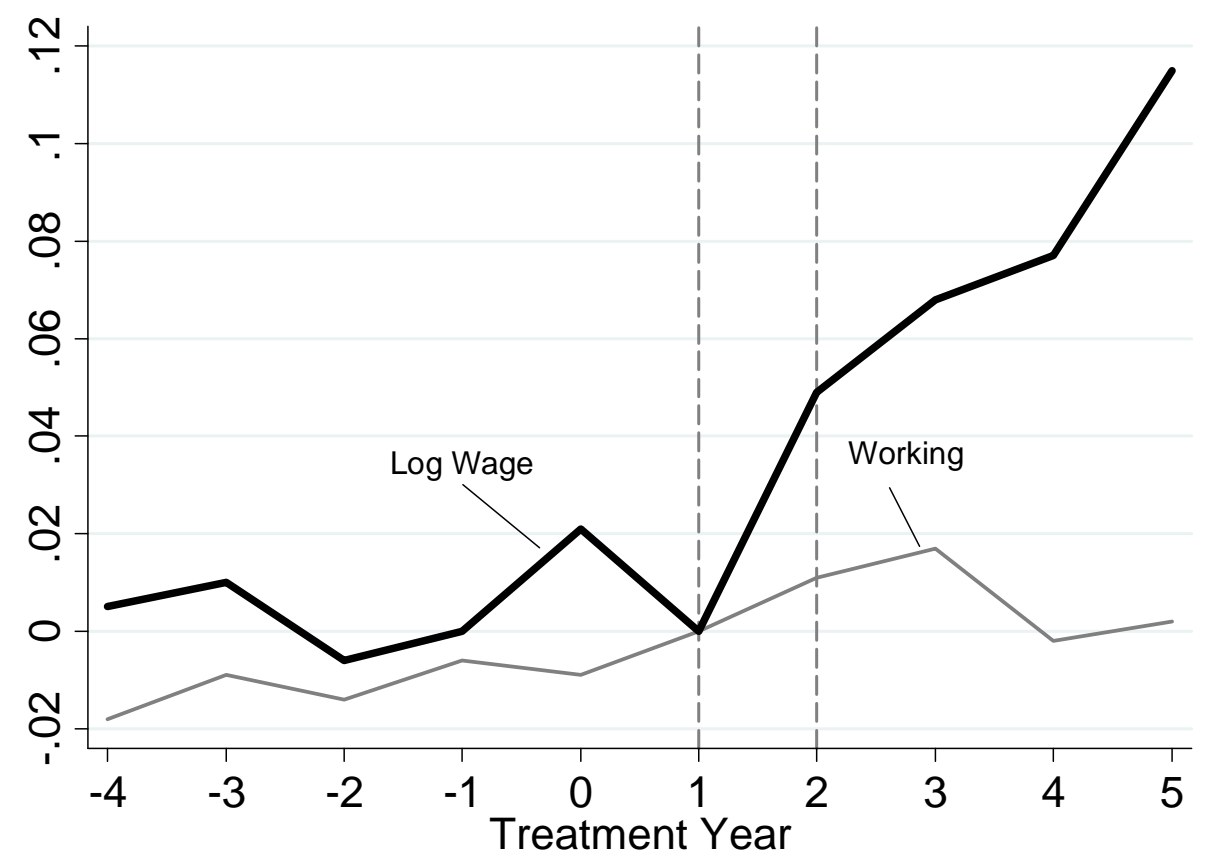

This figure shows the results of estimating a flexible version of equation [1], where I estimate effects for both preadoption years and post-adoption years. For each outcome, I plot the estimated coefficients of ITT years -4 through 5 (the first adoption cohort is year 0 and the first "fully treated" cohort is year 1) 
Figure 7: Effect on Earning a BA and Junior Year Attendance for Hispanic Students

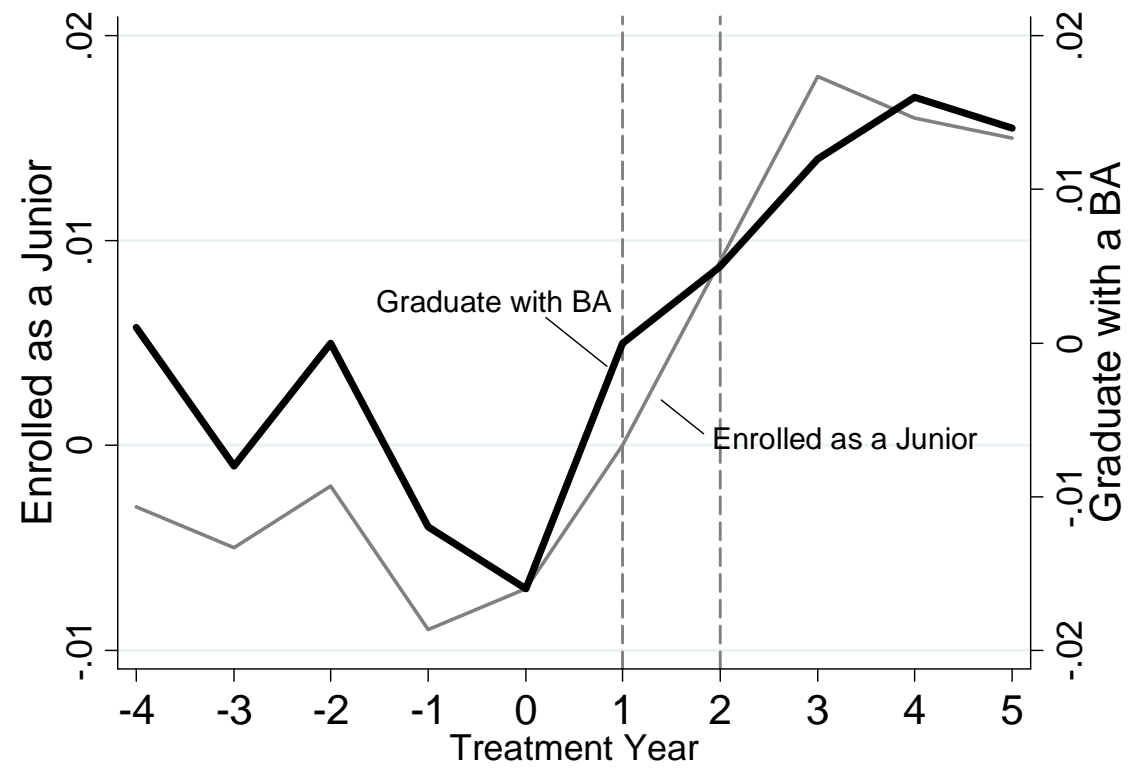

Based on the population of Hispanic students.

This figure shows the results of estimating a flexible version of equation [1], where I estimate effects for both preadoption years and post-adoption years. For each outcome, I plot the estimated coefficients of ITT years -4 through 5 (the first adoption cohort is year 0 and the first "fully treated" cohort is year 1)

Figure 8: Effect on Earning a BA and Junior Year Attendance for Black Students

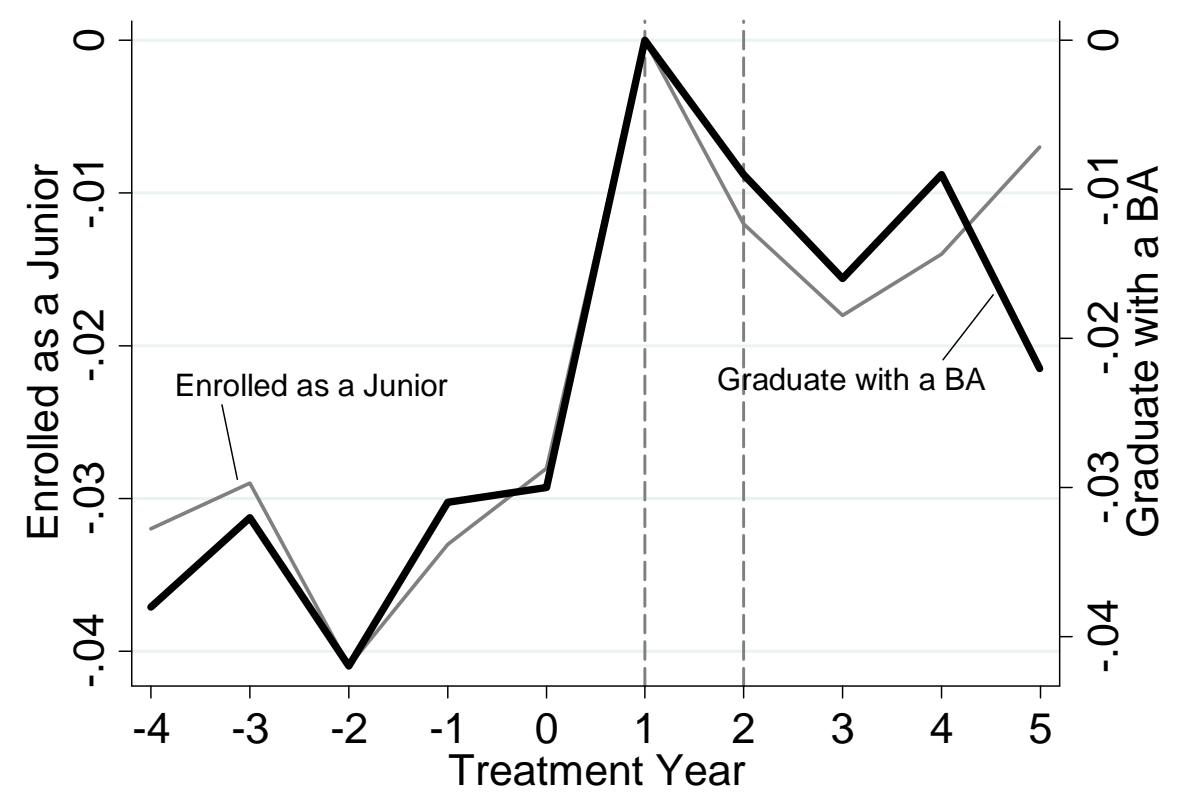

Based on the population of Black students

This figure shows the results of estimating a flexible version of equation [1], where I estimate effects for both preadoption years and post-adoption years. For each outcome, I plot the estimated coefficients of ITT years -4 through 5 (the first adoption cohort is year 0 and the first "fully treated" cohort is year 1) 
Table 1 Demographics for APIP schools and other comparison groups

\begin{tabular}{|c|c|c|c|c|}
\hline \multirow{4}{*}{ Enrollment } & \multicolumn{2}{|c|}{ APIP Schools } & \multicolumn{2}{|c|}{ Non-APIP Schools } \\
\hline & 1993-1999 & $2000-2005$ & 1993-1999 & $2000-2005$ \\
\hline & 1777.68 & 1836.36 & 716.85 & 751.56 \\
\hline & (642.34) & (648.86) & (781.97) & (833.36) \\
\hline \multirow[t]{2}{*}{ \% White } & 30.82 & 25.16 & 59.38 & 53.36 \\
\hline & (25.43) & (23.28) & (29.46) & (30.42) \\
\hline \multirow[t]{2}{*}{ \% Black } & 30.17 & 26.24 & 10.32 & 11.30 \\
\hline & (26.82) & (23.5) & (15.64) & (17.08) \\
\hline \multirow[t]{2}{*}{ \% Hispanic } & 35.76 & 45.36 & 28.92 & 33.67 \\
\hline & (23.49) & (23.84) & (28.9) & (29.5) \\
\hline \multirow[t]{2}{*}{$\%$ Asian } & 2.93 & 2.39 & 1.09 & 1.12 \\
\hline & (3.43) & (3.65) & (2.76) & (2.98) \\
\hline \multirow[t]{2}{*}{ \% Free lunch } & 34.33 & 41.60 & 30.42 & 35.51 \\
\hline & (22.3) & (25.0) & (23.97) & (26.25) \\
\hline \multirow[t]{2}{*}{ \% Limited English } & 9.66 & 10.68 & 3.57 & 3.83 \\
\hline & (12.89) & (11.86) & (7.71) & (6.8) \\
\hline \multirow[t]{2}{*}{ City } & 0.874 & 0.739 & 0.182 & 0.197 \\
\hline & $(0.28)$ & $(0.44)$ & $(0.39)$ & $(0.4)$ \\
\hline \multirow[t]{2}{*}{ Rural } & 0.000 & 0.017 & 0.489 & 0.373 \\
\hline & $(0.0)$ & $(0.13)$ & $(0.5)$ & $(0.48)$ \\
\hline Number of Schools & \multicolumn{2}{|c|}{58} & \multicolumn{2}{|c|}{1413} \\
\hline
\end{tabular}

Standard deviations in parentheses. 
Table 2 Student-Level Summary Statistics of APIP Schools Before and After APIP Adoption

\begin{tabular}{|c|c|c|c|c|c|c|}
\hline \multirow[t]{2}{*}{ Variable } & Obs. & Mean & Std. Dev. & Obs. & Mean & Std. Dev. \\
\hline & \multicolumn{3}{|c|}{ Not Adopted APIP } & \multicolumn{3}{|c|}{ Adopted APIP } \\
\hline Grade 10 Year & 156858 & 1998.678 & $(3.247)$ & 137704 & 2003.117 & $(3.335)$ \\
\hline LEP & 156858 & 0.112 & $(0.315)$ & 137704 & 0.138 & $(0.345)$ \\
\hline Low Income & 156858 & 0.384 & $(0.486)$ & 137704 & 0.459 & $(0.498)$ \\
\hline Black & 156858 & 0.206 & $(0.404)$ & 137704 & 0.270 & $(0.444)$ \\
\hline Hispanic & 156858 & 0.444 & $(0.497)$ & 137704 & 0.426 & $(0.494)$ \\
\hline Asian & 156858 & 0.034 & $(0.182)$ & 137704 & 0.037 & $(0.188)$ \\
\hline Native American & 156858 & 0.003 & $(0.059)$ & 137704 & 0.004 & $(0.062)$ \\
\hline Female & 156858 & 0.502 & $(0.5)$ & 137704 & 0.510 & $(0.5)$ \\
\hline Tenth-Grade Reading z-Score & 156858 & -0.092 & (1.018) & 137704 & -0.063 & $(0.987)$ \\
\hline Tenth-Grade Math z-score & 156858 & -0.091 & $(1.004)$ & 137704 & -0.078 & $(0.962)$ \\
\hline Take AP Course & 156858 & 0.229 & $(0.42)$ & 137704 & 0.304 & $(0.46)$ \\
\hline AP Courses Taken & 156858 & 0.652 & (1.539) & 137704 & 0.974 & $(1.947)$ \\
\hline Take AP Exam & 155753 & 0.055 & $(0.228)$ & 138535 & 0.068 & $(0.252)$ \\
\hline AP Exams Taken & 155753 & 0.097 & $(0.506)$ & 138535 & 0.127 & $(0.598)$ \\
\hline AP Exams Passed & 155753 & 0.047 & $(0.342)$ & 138535 & 0.054 & $(0.366)$ \\
\hline Freshman at Any School & 156858 & 0.592 & $(0.691)$ & 137704 & 0.570 & $(0.684)$ \\
\hline Ever Freshman at Private & 44157 & 0.020 & $(0.142)$ & 111838 & 0.041 & $(0.197)$ \\
\hline Ever Freshman at Four-year & 156858 & 0.174 & $(0.386)$ & 137704 & 0.177 & $(0.391)$ \\
\hline Ever Freshman at Two-year & 156858 & 0.418 & $(0.493)$ & 137704 & 0.392 & $(0.488)$ \\
\hline Attend College outside TX & 2018 & 0.045 & $(0.208)$ & 42293 & 0.037 & $(0.189)$ \\
\hline Attend College in TX & 2018 & 0.398 & $(0.49)$ & 42293 & 0.421 & $(0.494)$ \\
\hline Freshman Year GPA & 58685 & 2.382 & $(1.176)$ & 44425 & 2.427 & (1.192) \\
\hline Sophomore at Any School & 156858 & 0.314 & $(0.561)$ & 115783 & 0.310 & $(0.562)$ \\
\hline Junior at Any School & 154840 & 0.164 & $(0.375)$ & 95411 & 0.155 & $(0.366)$ \\
\hline Graduate with a BA & 147779 & 0.146 & $(0.354)$ & 80931 & 0.115 & $(0.319)$ \\
\hline Graduate with an AA & 156858 & 0.038 & $(0.191)$ & 115783 & 0.021 & $(0.142)$ \\
\hline Working 2010 & 156858 & 0.4925 & $(0.500)$ & 160776 & 0.46774 & $(0.498)$ \\
\hline Wage in 2010 (4th quarter) & 77263 & 8029.6 & (7990) & 75202 & 4895.2 & $(4616)$ \\
\hline
\end{tabular}


Table 3 Regression Estimates: Effect of APIP Adoption Years on Short-run and Long-run Outcomes

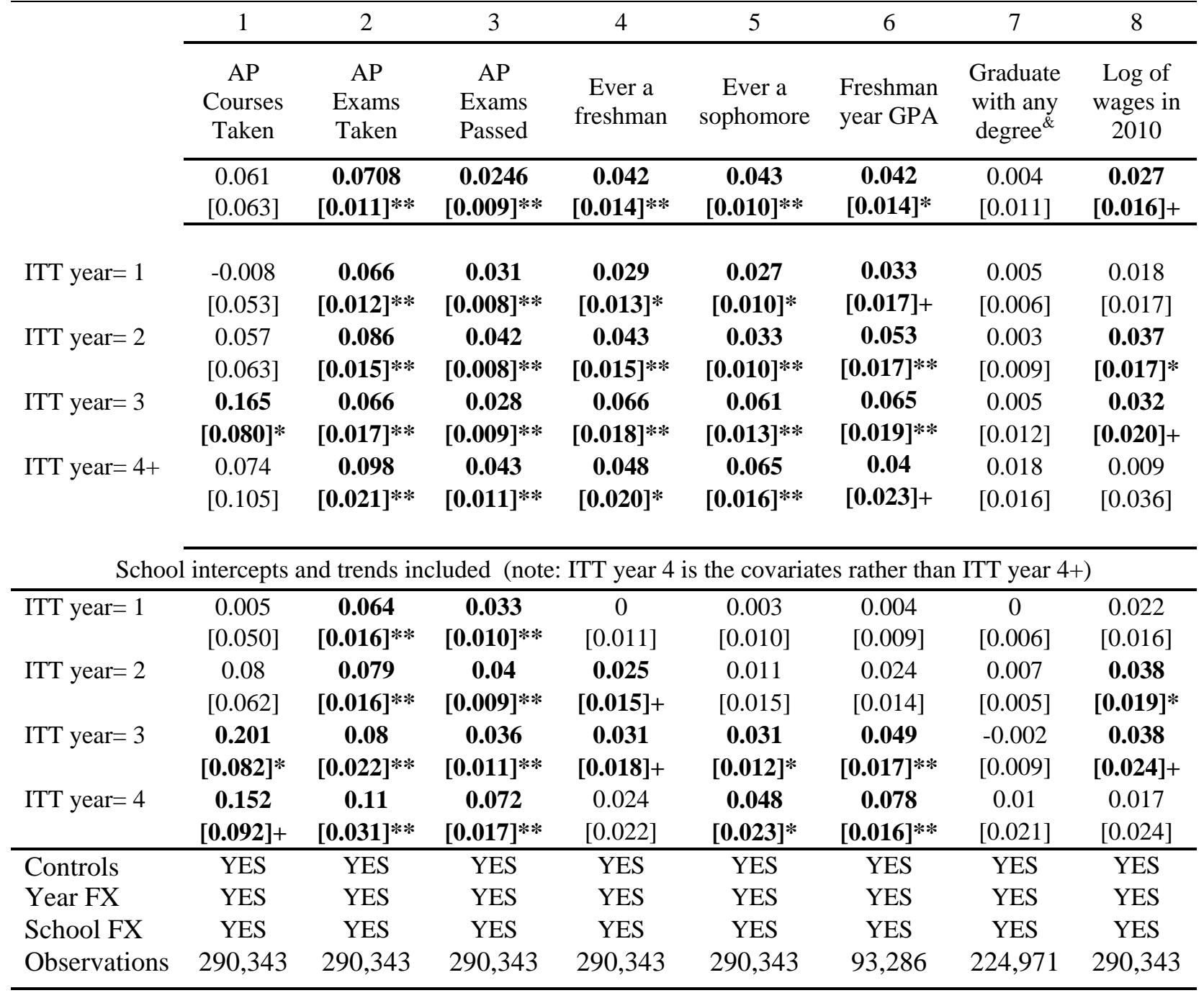

Heteroskedasticity robust standard errors in parentheses are adjusted for clustering at the school level.

+significant at 10 percent; * significant at 5 percent; ** significant at 1 percent. All models include cohort-fixed effects and high school-fixed effects. All models except the top panel include the full set of controls, as in Table 3.

${ }^{\&}$ Note that the college graduation outcome is only analyzed on the sample of students who were expected to graduate from high school before 2005. 
Table 4 Estimates of the Effect of APIP Adoption Duration on Outcomes: By Sub-sample

\begin{tabular}{|c|c|c|c|c|c|c|c|}
\hline & 1 & 2 & 3 & 4 & 5 & 6 & 7 \\
\hline & $\begin{array}{c}\text { AP Courses } \\
\text { Taken }\end{array}$ & $\begin{array}{c}\text { AP Exams } \\
\text { Passed }\end{array}$ & $\begin{array}{c}\text { Ever a } \\
\text { Freshman }\end{array}$ & $\begin{array}{c}\text { Ever a } \\
\text { Sophomore }\end{array}$ & $\begin{array}{c}\text { Graduate } \\
\text { from } \\
\text { College }\end{array}$ & $\begin{array}{c}\text { Working in } \\
2010\end{array}$ & $\begin{array}{c}\text { Log wage } \\
\text { in } 2010\end{array}$ \\
\hline & \multicolumn{7}{|c|}{ High Likelihood of Taking AP Courses } \\
\hline \multirow[t]{2}{*}{ Treated } & $\begin{array}{c}0.203 \\
{[0.178]}\end{array}$ & $\begin{array}{c}0.179 \\
{[0.108]+}\end{array}$ & $\begin{array}{c}0.08 \\
{[0.027]^{* *}}\end{array}$ & $\begin{array}{c}0.092 \\
{[0.024]^{* *}}\end{array}$ & $\begin{array}{c}0.018 \\
{[0.011]+}\end{array}$ & $\begin{array}{c}0.027 \\
{[0.013]^{*}}\end{array}$ & $\begin{array}{c}0.057 \\
{[0.027]^{*}}\end{array}$ \\
\hline & \multicolumn{7}{|c|}{ Low Likelihood of Taking AP Courses } \\
\hline \multirow[t]{2}{*}{ Treated } & $\begin{array}{c}-0.052 \\
{[0.035]}\end{array}$ & $\begin{array}{c}0.003 \\
{[0.004]}\end{array}$ & $\begin{array}{c}0.009 \\
{[0.012]}\end{array}$ & $\begin{array}{c}0.008 \\
{[0.006]}\end{array}$ & $\begin{array}{c}-0.004 \\
{[0.003]}\end{array}$ & $\begin{array}{c}0.017 \\
{[0.016]}\end{array}$ & $\begin{array}{c}-0.012 \\
{[0.040]}\end{array}$ \\
\hline & \multicolumn{7}{|c|}{ High AP Course Capacity before Adoption } \\
\hline \multirow[t]{2}{*}{ Treated } & $\begin{array}{c}0.135 \\
{[0.064]^{*}}\end{array}$ & $\begin{array}{c}0.047 \\
{[0.011]^{* *}}\end{array}$ & $\begin{array}{c}0.047 \\
{[0.021]^{*}}\end{array}$ & $\begin{array}{c}0.06 \\
{[0.012]^{* *}}\end{array}$ & $\begin{array}{c}0.005 \\
{[0.009]}\end{array}$ & $\begin{array}{c}0.025 \\
{[0.013]+}\end{array}$ & $\begin{array}{c}0.042 \\
{[0.023]+}\end{array}$ \\
\hline & \multicolumn{7}{|c|}{ Low AP Course Capacity before Adoption } \\
\hline \multirow[t]{2}{*}{ Treated } & $\begin{array}{c}-0.01 \\
{[0.116]}\end{array}$ & $\begin{array}{c}0.0362 \\
{[0.008]^{* *}}\end{array}$ & $\begin{array}{c}0.027 \\
{[0.017]}\end{array}$ & $\begin{array}{c}-0.009 \\
{[0.013]}\end{array}$ & $\begin{array}{c}-0.011 \\
{[0.008]}\end{array}$ & $\begin{array}{c}0.016 \\
{[0.015]}\end{array}$ & $\begin{array}{c}-0.006 \\
{[0.029]}\end{array}$ \\
\hline & \multicolumn{7}{|c|}{ High-Power Incentives } \\
\hline \multirow[t]{2}{*}{ Treated } & $\begin{array}{c}0.135 \\
{[0.058]^{*}}\end{array}$ & $\begin{array}{c}0.022 \\
{[0.009]^{*}}\end{array}$ & $\begin{array}{c}0.036 \\
{[0.021]+}\end{array}$ & $\begin{array}{c}0.055 \\
{[0.013]^{* *}}\end{array}$ & $\begin{array}{c}0.011 \\
{[0.011]}\end{array}$ & $\begin{array}{c}0.004 \\
{[0.014]}\end{array}$ & $\begin{array}{c}0.054 \\
{[0.031]+}\end{array}$ \\
\hline & \multicolumn{7}{|c|}{ Low-Power Incentives } \\
\hline Treated & $\begin{array}{c}-0.025 \\
{[0.087]}\end{array}$ & $\begin{array}{c}0.027 \\
{[0.010]^{*}}\end{array}$ & $\begin{array}{c}0.044 \\
{[0.021]^{*}}\end{array}$ & $\begin{array}{c}0.006 \\
{[0.013]}\end{array}$ & $\begin{array}{c}-0.012 \\
{[0.008]}\end{array}$ & $\begin{array}{c}0.035 \\
{[0012]^{* *}}\end{array}$ & $\begin{array}{c}-0.006 \\
{[0.025]}\end{array}$ \\
\hline
\end{tabular}

Heteroskedasticity robust standard errors in brackets are adjusted for clustering at the school level.

+ significant at 10 percent; * significant at 5 percent; ** significant at 1 percent.

All regressions control for tenth-grade test scores, ethnicity, gender, LEP status, and free or reduced lunch status. 
Table 5 Regression Estimates: Effect of APIP Program on Predicted Outcomes

\begin{tabular}{ccccccc}
\hline & 1 & 2 & 3 & 4 & 5 & 6 \\
\cline { 2 - 7 } & $\begin{array}{c}\text { Predicted: AP } \\
\text { Courses }\end{array}$ & $\begin{array}{c}\text { Predicted: AP } \\
\text { Exams }\end{array}$ & $\begin{array}{c}\text { Predicted: } \\
\text { Attend College }\end{array}$ & $\begin{array}{c}\text { Predicted: } \\
\text { Sophomore }\end{array}$ & $\begin{array}{c}\text { Predicted: } \\
\text { College } \\
\text { Graduate }\end{array}$ & $\begin{array}{c}\text { Predicted: log } \\
\text { wages in } \\
2010\end{array}$ \\
\cline { 2 - 7 } Adopted & 0.01 & -0.004 & -0.001 & -0.002 & -0.002 & 0.001 \\
ITT year>0 & {$[0.032]$} & {$[0.040]$} & {$[0.006]$} & {$[0.007]$} & {$[0.003]$} & {$[0.007]$} \\
& & & & & & \\
\hline ITT year=1 & 0.002 & -0.007 & -0.003 & 0.000 & -0.002 & 0.001 \\
& {$[0.026]$} & {$[0.024]$} & {$[0.005]$} & {$[0.006]$} & {$[0.003]$} & {$[0.007]$} \\
ITT year=2 & 0.015 & 0.004 & -0.005 & 0.005 & -0.002 & 0.001 \\
& {$[0.038]$} & {$[0.045]$} & {$[0.006]$} & {$[0.008]$} & {$[0.003]$} & {$[0.007]$} \\
ITT year=3 & 0.014 & -0.024 & -0.005 & 0.005 & -0.002 & 0.001 \\
& {$[0.041]$} & {$[0.039]$} & {$[0.006]$} & {$[0.008]$} & {$[0.003]$} & {$[0.007]$} \\
ITT year=4+ & 0.018 & 0.017 & -0.007 & -0.002 & -0.002 & 0.001 \\
& {$[0.048]$} & {$[0.052]$} & {$[0.007]$} & {$[0.010]$} & {$[0.003]$} & {$[0.007]$} \\
School FX & YES & YES & YES & YES & YES & YES \\
Year FX & YES & YES & YES & YES & YES & YES \\
Observations & 290343 & 290343 & 290343 & 290343 & 290343 & 290343 \\
\hline
\end{tabular}

Heteroskedasticity robust standard errors in brackets are adjusted for clustering at the school level.

+ significant at 10 percent; * significant at 5 percent; ** significant at 1 percent.

All regressions control for tenth-grade test scores, ethnicity, gender, LEP status, and free or reduced lunch status. 
Table 6 Regression Estimates: Effect of Years of APIP Adoption on Longer-run College Outcomes by Ethnicity

\begin{tabular}{|c|c|c|c|c|c|c|c|c|c|c|}
\hline & 1 & 2 & 3 & 4 & 5 & 6 & 7 & 8 & 9 & 12 \\
\hline & DID & DID & DID & DID & DID & DID & DID & DID & $\begin{array}{l}\text { DID with } \\
\text { Trends }\end{array}$ & $\begin{array}{c}\text { DID with } \\
\text { Trends }\end{array}$ \\
\hline & $\begin{array}{c}\text { Ever a } \\
\text { freshman }\end{array}$ & $\begin{array}{c}\text { Ever a } \\
\text { sophomore }\end{array}$ & $\begin{array}{l}\text { Ever a } \\
\text { Junior }\end{array}$ & $\begin{array}{c}\text { Total } \\
\text { Credits }\end{array}$ & $\begin{array}{c}\text { Any } \\
\text { degree }\end{array}$ & BA & $\begin{array}{c}\text { Working in } \\
2010 \text { (all } \\
\text { cohorts) }\end{array}$ & $\begin{array}{l}\text { Log Wage } \\
\text { in } 2010 \text { (all } \\
\text { cohorts) }\end{array}$ & $\begin{array}{l}\text { Log Wage } \\
\text { in } 2010 \text { (all } \\
\text { cohorts) }\end{array}$ & $\begin{array}{c}\text { Log Wage } \\
\text { in } 2010 \\
\text { (early } \\
\text { cohorts) }\end{array}$ \\
\hline & \multicolumn{10}{|c|}{ Black (54059 observations) } \\
\hline ITT year $=1$ & $\begin{array}{c}0.001 \\
{[0.026]}\end{array}$ & $\begin{array}{c}0.011 \\
{[0.014]}\end{array}$ & $\begin{array}{c}0.016 \\
{[0.009]+}\end{array}$ & $\begin{array}{c}3.131 \\
{[2.819]}\end{array}$ & $\begin{array}{c}0.016 \\
{[0.010]}\end{array}$ & $\begin{array}{c}0.018 \\
{[0.009]^{*}}\end{array}$ & $\begin{array}{c}0.013 \\
{[0.017]}\end{array}$ & $\begin{array}{c}-0.007 \\
{[0.036]}\end{array}$ & $\begin{array}{c}0.003 \\
{[0.027]}\end{array}$ & $\begin{array}{c}-0.082 \\
{[0.056]}\end{array}$ \\
\hline ITT year $=2$ & $\begin{array}{c}0.013 \\
{[0.022]}\end{array}$ & $\begin{array}{c}0.011 \\
{[0.013]}\end{array}$ & $\begin{array}{c}0.011 \\
{[0.008]}\end{array}$ & $\begin{array}{c}3.461 \\
{[2.247]}\end{array}$ & $\begin{array}{c}0.01 \\
{[0.011]}\end{array}$ & $\begin{array}{c}0.011 \\
{[0.011]}\end{array}$ & $\begin{array}{c}0.018 \\
{[0.014]}\end{array}$ & $\begin{array}{c}0.069 \\
{[0.052]}\end{array}$ & $\begin{array}{c}0.024 \\
{[0.034]}\end{array}$ & $\begin{array}{c}-0.003 \\
{[0.055]}\end{array}$ \\
\hline ITT year $=3$ & $\begin{array}{c}0.038 \\
{[0.021]+}\end{array}$ & $\begin{array}{c}0.034 \\
{[0.014]^{*}}\end{array}$ & $\begin{array}{c}0.017 \\
{[0.010]+}\end{array}$ & $\begin{array}{c}7.68 \\
{[2.600]^{* *}}\end{array}$ & $\begin{array}{c}0.017 \\
{[0.012]}\end{array}$ & $\begin{array}{c}0.018 \\
{[0.011]+}\end{array}$ & $\begin{array}{c}0.018 \\
{[0.019]}\end{array}$ & $\begin{array}{c}0.093 \\
{[0.051]+}\end{array}$ & $\begin{array}{c}0.054 \\
{[0.026]^{*}}\end{array}$ & $\begin{array}{c}0.009 \\
{[0.056]}\end{array}$ \\
\hline \multirow[t]{2}{*}{ ITT year $=4+$} & $\begin{array}{c}-0.012 \\
{[0.025]}\end{array}$ & $\begin{array}{c}0.047 \\
{[0.020]^{*}}\end{array}$ & $\begin{array}{c}0.012 \\
{[0.012]}\end{array}$ & $\begin{array}{c}5.997 \\
{[3.674]}\end{array}$ & $\begin{array}{c}0.003 \\
{[0.012]}\end{array}$ & $\begin{array}{c}0.01 \\
{[0.011]}\end{array}$ & $\begin{array}{c}0.01 \\
{[0.022]}\end{array}$ & $\begin{array}{c}0.145 \\
{[0.041]^{* *}}\end{array}$ & $\begin{array}{c}0.082 \\
{[0.046]+}\end{array}$ & $\begin{array}{c}0.01 \\
{[0.044]}\end{array}$ \\
\hline & \multicolumn{10}{|c|}{ Hispanic (93171) } \\
\hline ITT year $=1$ & $\begin{array}{c}0.015 \\
{[0.016]}\end{array}$ & $\begin{array}{c}0.021 \\
{[0.013]}\end{array}$ & $\begin{array}{c}0.013 \\
{[0.006]^{*}}\end{array}$ & $\begin{array}{c}1.68 \\
{[2.025]}\end{array}$ & $\begin{array}{c}0.011 \\
{[0.006]+}\end{array}$ & $\begin{array}{c}0.012 \\
{[0.005]^{*}}\end{array}$ & $\begin{array}{c}0.01 \\
{[0.012]}\end{array}$ & $\begin{array}{c}0.043 \\
{[0.022]+}\end{array}$ & $\begin{array}{c}0.033 \\
{[0.026]}\end{array}$ & $\begin{array}{c}0.047 \\
{[0.043]}\end{array}$ \\
\hline ITT year $=2$ & $\begin{array}{c}0.03 \\
{[0.018]}\end{array}$ & $\begin{array}{c}0.035 \\
{[0.014]^{*}}\end{array}$ & $\begin{array}{c}0.022 \\
{[0.008]^{* *}}\end{array}$ & $\begin{array}{c}4.561 \\
{[2.372]+}\end{array}$ & $\begin{array}{c}0.018 \\
{[0.010]+}\end{array}$ & $\begin{array}{c}0.022 \\
{[0.008]^{*}}\end{array}$ & $\begin{array}{c}0.015 \\
{[0.014]}\end{array}$ & $\begin{array}{c}0.033 \\
{[0.024]}\end{array}$ & $\begin{array}{c}0.023 \\
{[0.045]}\end{array}$ & $\begin{array}{c}0.072 \\
{[0.046]}\end{array}$ \\
\hline ITT year $=3$ & $\begin{array}{c}0.027 \\
{[0.021]}\end{array}$ & $\begin{array}{c}0.052 \\
{[0.014]^{* *}}\end{array}$ & $\begin{array}{c}0.021 \\
{[0.007]^{* *}}\end{array}$ & $\begin{array}{c}6.828 \\
{[1.949]^{* *}}\end{array}$ & $\begin{array}{c}0.024 \\
{[0.010]^{*}}\end{array}$ & $\begin{array}{c}0.026 \\
{[0.010]^{*}}\end{array}$ & $\begin{array}{c}0.014 \\
{[0.016]}\end{array}$ & $\begin{array}{c}0.038 \\
{[0.030]}\end{array}$ & $\begin{array}{c}0.042 \\
{[0.024]+}\end{array}$ & $\begin{array}{c}0.14 \\
{[0.050]^{* *}}\end{array}$ \\
\hline ITT year= 4+ & $\begin{array}{c}0.016 \\
{[0.028]}\end{array}$ & $\begin{array}{c}0.062 \\
{[0.019]^{* *}} \\
\end{array}$ & $\begin{array}{c}0.021 \\
{[0.009]^{*}}\end{array}$ & $\begin{array}{c}4.793 \\
{[2.878]}\end{array}$ & $\begin{array}{c}0.023 \\
{[0.012]+} \\
\end{array}$ & $\begin{array}{c}0.025 \\
{[0.011]^{*}}\end{array}$ & $\begin{array}{c}0.021 \\
{[0.024]}\end{array}$ & $\begin{array}{c}0.081 \\
{[0.033]^{*}}\end{array}$ & $\begin{array}{c}0.051 \\
{[0.027]+}\end{array}$ & $\begin{array}{c}0.117 \\
{[0.056]^{*}}\end{array}$ \\
\hline & \multicolumn{10}{|c|}{ White (68722) } \\
\hline ITT year= 1 & $\begin{array}{c}0.041 \\
{[0.024]+}\end{array}$ & $\begin{array}{c}0.038 \\
{[0.015]^{*}}\end{array}$ & $\begin{array}{c}0.024 \\
{[0.011]^{*}}\end{array}$ & $\begin{array}{c}4.909 \\
{[3.004]}\end{array}$ & $\begin{array}{c}0.004 \\
{[0.009]}\end{array}$ & $\begin{array}{c}0.01 \\
{[0.009]}\end{array}$ & $\begin{array}{c}0.011 \\
{[0.012]}\end{array}$ & $\begin{array}{c}0.044 \\
{[0.026]+}\end{array}$ & $\begin{array}{c}0.041 \\
{[0.024]+}\end{array}$ & $\begin{array}{c}-0.019 \\
{[0.032]}\end{array}$ \\
\hline ITT year $=2$ & $\begin{array}{c}0.064 \\
{[0.025]^{*}}\end{array}$ & $\begin{array}{c}0.042 \\
{[0.017]^{*}}\end{array}$ & $\begin{array}{c}0.024 \\
{[0.012]+}\end{array}$ & $\begin{array}{c}6.505 \\
{[2.679]^{*}}\end{array}$ & $\begin{array}{c}0.004 \\
{[0.011]}\end{array}$ & $\begin{array}{c}0.013 \\
{[0.012]}\end{array}$ & $\begin{array}{c}0.019 \\
{[0.012]}\end{array}$ & $\begin{array}{c}0.109 \\
{[0.035]^{* *}}\end{array}$ & $\begin{array}{c}0.077 \\
{[0.037]^{*}}\end{array}$ & $\begin{array}{c}-0.01 \\
{[0.059]}\end{array}$ \\
\hline ITT year $=3$ & $\begin{array}{c}0.078 \\
{[0.029]^{* *}}\end{array}$ & $\begin{array}{c}0.075 \\
{[0.021]^{* *}}\end{array}$ & $\begin{array}{c}0.027 \\
{[0.016]+}\end{array}$ & $\begin{array}{c}9.038 \\
{[2.763]^{* *}}\end{array}$ & $\begin{array}{c}-0.005 \\
{[0.012]}\end{array}$ & $\begin{array}{c}0.005 \\
{[0.013]}\end{array}$ & $\begin{array}{c}0.041 \\
{[0.015]^{* *}}\end{array}$ & $\begin{array}{c}0.074 \\
{[0.040]+}\end{array}$ & $\begin{array}{c}0.084 \\
{[0.040]^{*}}\end{array}$ & $\begin{array}{c}-0.062 \\
{[0.078]}\end{array}$ \\
\hline ITT year= 4+ & $\begin{array}{c}0.074 \\
{[0.034]^{*}}\end{array}$ & $\begin{array}{c}0.089 \\
{[0.023]^{* *}}\end{array}$ & $\begin{array}{c}0.024 \\
{[0.017]}\end{array}$ & $\begin{array}{c}7.107 \\
{[2.815]^{*}}\end{array}$ & $\begin{array}{c}-0.017 \\
{[0.018]}\end{array}$ & $\begin{array}{c}-0.011 \\
{[0.018]}\end{array}$ & $\begin{array}{c}0.037 \\
{[0.016]^{*}}\end{array}$ & $\begin{array}{c}0.032 \\
{[0.045]}\end{array}$ & $\begin{array}{c}0.047 \\
{[0.052]}\end{array}$ & $\begin{array}{c}-0.038 \\
{[0.080]}\end{array}$ \\
\hline
\end{tabular}

Heteroskedasticity robust standard errors in brackets are adjusted for clustering at the school level.

+ significant at 10 percent; * significant at 5 percent; ** significant at 1 percent.

All regressions control for tenth-grade test scores, gender, ethnicity, LEP status, and free or reduced lunch status. 


\section{Appendix}

\section{Appendix Table A1: Effect on AP Exam Subjects Taken}

\begin{tabular}{lccccc}
\multicolumn{5}{c}{ Effects on Log AP Exam Taking at School in a Given Year: By Subject } \\
\hline & \multicolumn{1}{c}{1} & 2 & 3 & 4 & 5 \\
\cline { 2 - 6 } & Math and Computer & & Social Sciences and & & Art and \\
& Science & English & History & Science & Music \\
\cline { 2 - 6 } ITT year= 1 & 0.084 & 0.285 & 0.013 & 0.134 & -0.16 \\
& {$[0.138]$} & {$\left[0.133^{*}\right.$} & {$[0.155]$} & {$[0.129]$} & {$[0.22]$} \\
ITT year= 2 & 0.082 & 0.403 & 0.081 & 0.028 & -0.037 \\
& {$[0.211]$} & {$[0.200]^{*}$} & {$[0.261]$} & {$[0.176]$} & {$[0.365]$} \\
ITT year= 3 & 0.294 & 0.677 & 0.244 & 0.441 & 0.38 \\
& {$[0.204]$} & {$[0.204]^{* *}$} & {$[0.305]$} & {$[0.213]^{*}$} & {$[0.423]$} \\
ITT year= 4+ & 0.214 & 0.804 & 0.284 & 0.803 & 0.289 \\
& {$[0.25]$} & {$[0.238]^{* *}$} & {$[0.326]$} & {$[0.218]^{* *}$} & {$[0.328]$} \\
Observations & 570 & 570 & 570 & 570 & 570 \\
\hline
\end{tabular}

Heteroskedasticity robust standard errors in brackets are adjusted for clustering at the school level.

* significant at 5 percent; ** significant at 1 percent. All regressions include school- and year-fixed effects.

Table A2

Regression Estimates: Effect of Years of APIP Adoption on AP Course Taking and College Enrollment

\begin{tabular}{|c|c|c|c|c|c|c|c|c|c|}
\hline & 1 & 2 & 3 & 4 & 5 & 6 & 7 & 8 & 9 \\
\hline & \multicolumn{3}{|c|}{ TEA Data } & \multicolumn{4}{|c|}{ Texas Higher Education Data } & \multicolumn{2}{|c|}{ NSC Data } \\
\hline & $\begin{array}{c}\text { AP } \\
\text { Courses } \\
\text { Taken } \\
\end{array}$ & $\begin{array}{c}\text { AP } \\
\text { Exams } \\
\text { Taken } \\
\end{array}$ & $\begin{array}{c}\text { AP } \\
\text { Exams } \\
\text { Passed } \\
\end{array}$ & $\begin{array}{c}\text { Ever } \\
\text { Freshman }\end{array}$ & $\begin{array}{c}\text { Ever } \\
\text { Freshman } \\
\text { at 2-yr }\end{array}$ & $\begin{array}{c}\text { Ever } \\
\text { Freshman } \\
\text { at 4-yr }\end{array}$ & $\begin{array}{c}\text { Ever } \\
\text { Freshman } \\
\text { at Private }\end{array}$ & $\begin{array}{c}\text { Enrolled } \\
\text { Out-of - } \\
\text { State }\end{array}$ & $\begin{array}{l}\text { Enrolled } \\
\text { In-State }\end{array}$ \\
\hline $\begin{array}{l}\text { Adopted } \\
(\text { ITT year }>0)\end{array}$ & $\begin{array}{c}0.061 \\
{[0.063]} \\
\end{array}$ & $\begin{array}{c}0.0708 \\
{[0.011]^{* *}}\end{array}$ & $\begin{array}{c}0.0246 \\
{[0.009]^{* *}}\end{array}$ & $\begin{array}{c}0.042 \\
{[0.014]^{* *}}\end{array}$ & $\begin{array}{c}0.019 \\
{[0.010]+} \\
\end{array}$ & $\begin{array}{c}0.023 \\
{[0.008]^{* *}} \\
\end{array}$ & $\begin{array}{c}0.015 \\
{[0.005]^{* *}}\end{array}$ & $\begin{array}{c}-0.001 \\
{[0.015]} \\
\end{array}$ & $\begin{array}{c}0.021 \\
{[0.015]} \\
\end{array}$ \\
\hline ITT year=1 & $\begin{array}{c}-0.008 \\
{[0.053]}\end{array}$ & $\begin{array}{c}0.066 \\
{[0.012]^{* *}}\end{array}$ & $\begin{array}{c}0.031 \\
{[0.008]^{* *}}\end{array}$ & $\begin{array}{c}0.029 \\
{[0.013]^{*}}\end{array}$ & $\begin{array}{c}0.013 \\
{[0.010]}\end{array}$ & $\begin{array}{c}0.016 \\
{[0.007]^{*}}\end{array}$ & $\begin{array}{c}0.011 \\
{[0.004]^{*}}\end{array}$ & $\begin{array}{c}-0.0002 \\
{[0.0146]}\end{array}$ & $\begin{array}{c}0.016 \\
{[0.014]}\end{array}$ \\
\hline ITT year $=2$ & $\begin{array}{c}0.057 \\
{[0.063]}\end{array}$ & $\begin{array}{c}0.086 \\
{[0.015]^{* *}}\end{array}$ & $\begin{array}{c}0.042 \\
{[0.008]^{* *}}\end{array}$ & $\begin{array}{c}0.043 \\
{[0.015]^{* *}}\end{array}$ & $\begin{array}{c}0.02 \\
{[0.011]+}\end{array}$ & $\begin{array}{c}0.023 \\
{[0.008]^{* *}}\end{array}$ & $\begin{array}{c}0.014 \\
{[0.005]^{*}}\end{array}$ & $\begin{array}{c}-0.001 \\
{[0.015]}\end{array}$ & $\begin{array}{c}0.035 \\
{[0.017]^{*}}\end{array}$ \\
\hline ITT year=3 & $\begin{array}{c}0.165 \\
{[0.080]^{*}}\end{array}$ & $\begin{array}{c}0.066 \\
{[0.017]^{* *}}\end{array}$ & $\begin{array}{c}0.028 \\
{[0.009]^{* *}}\end{array}$ & $\begin{array}{c}0.066 \\
{[0.018]^{* *}}\end{array}$ & $\begin{array}{c}0.033 \\
{[0.013]^{*}}\end{array}$ & $\begin{array}{c}0.034 \\
{[0.011]^{* *}}\end{array}$ & $\begin{array}{c}0.021 \\
{[0.007]^{* *}}\end{array}$ & $\begin{array}{l}- \\
-\end{array}$ & - \\
\hline ITT year=4+ & $\begin{array}{c}0.074 \\
{[0.105]}\end{array}$ & $\begin{array}{c}0.098 \\
{[0.021]^{* *}}\end{array}$ & $\begin{array}{c}0.043 \\
{[0.011]^{* *}}\end{array}$ & $\begin{array}{c}0.048 \\
{[0.020]^{*}}\end{array}$ & $\begin{array}{c}0.02 \\
{[0.015]}\end{array}$ & $\begin{array}{c}0.028 \\
{[0.014]+}\end{array}$ & $\begin{array}{c}0.018 \\
{[0.007]^{* *}}\end{array}$ & $\begin{array}{l}- \\
-\end{array}$ & - \\
\hline Controls & YES & YES & YES & YES & YES & YES & YES & YES & YES \\
\hline Year FX & YES & YES & YES & YES & YES & YES & YES & YES & YES \\
\hline School FX & YES & YES & YES & YES & YES & YES & YES & YES & YES \\
\hline F-test & 0.011 & $>0.000$ & $>0.000$ & 0.007 & 0.087 & 0.021 & 0.001 & 0.81 & 0.17 \\
\hline Observations & 290,343 & 290,343 & 290,343 & 290,343 & 290,343 & 290,343 & 290,343 & 44,311 & 44,311 \\
\hline
\end{tabular}

Heteroskedasticity robust standard errors in brackets are adjusted for clustering at the school level.

${ }^{* *} \mathrm{p}<0.01,{ }^{*} \mathrm{p}<0.05,+\mathrm{p}<0.1$

All regressions control for tenth-grade test scores, ethnicity, gender, LEP status, and free or reduced lunch status. 


\section{Appendix Table A3: Principal Turnover and APIP adoption}

\begin{tabular}{lcccccc} 
& 1 & 2 & 3 & 4 & 5 & 6 \\
\cline { 2 - 6 } & $\begin{array}{c}\text { Principal } \\
\text { turnover(t-3) }\end{array}$ & $\begin{array}{c}\text { Principal } \\
\text { turnover(t-2) }\end{array}$ & $\begin{array}{c}\text { Principal } \\
\text { turnover(t-1) }\end{array}$ & $\begin{array}{c}\text { Principal } \\
\text { turnover(t) }\end{array}$ & $\begin{array}{c}\text { Principal } \\
\text { turnover(t+1) }\end{array}$ & $\begin{array}{c}\text { Principal } \\
\text { turnover(t+2) }\end{array}$ \\
\cline { 2 - 7 } Adopted & 0.004 & 0.058 & 0.003 & 0.026 & 0.004 & -0.092 \\
ITT year>0 & {$[0.059]$} & {$[0.066]$} & {$[0.046]$} & {$[0.055]$} & {$[0.068]$} & {$[0.070]$} \\
Observations & 411 & 466 & 473 & 583 & 530 & 580 \\
\hline
\end{tabular}

Heteroskedasticity robust standard errors in brackets are adjusted for clustering at the school level.

* significant at 5 percent; ** significant at 1 percent. All regressions include school- and year-fixed effects.

\section{Appendix Table A4}

\begin{tabular}{|c|c|c|c|c|c|c|c|c|c|}
\hline & 1 & 2 & 3 & 4 & 5 & 6 & 7 & 8 & 9 \\
\hline & $\begin{array}{c}\text { High } \\
\text { School } \\
\text { Diploma }\end{array}$ & $\begin{array}{c}\text { Teacher } \\
\text { Turnover } \\
\text { (Proportion) }\end{array}$ & $\begin{array}{l}\text { Principal } \\
\text { turnover }\end{array}$ & $\begin{array}{c}\text { Log } \\
\text { Expenditure } \\
\text { on } \\
\text { Instruction }\end{array}$ & $\begin{array}{l}\text { Log Total } \\
\text { Expenditure }\end{array}$ & $\begin{array}{l}\text { Number } \\
\text { of AP } \\
\text { Teachers }\end{array}$ & $\begin{array}{l}\text { Number } \\
\text { of Non } \\
\text { AP } \\
\text { Teachers }\end{array}$ & $\begin{array}{c}\text { Mean } \\
\text { Teacher } \\
\text { Experience }\end{array}$ & $\begin{array}{l}\text { Mean } \\
\text { Class } \\
\text { Size }\end{array}$ \\
\hline ITT years $=1$ & $\begin{array}{c}0.01 \\
{[0.01]}\end{array}$ & $\begin{array}{c}0.014 \\
{[0.013]}\end{array}$ & $\begin{array}{l}-0.021 \\
{[0.077]}\end{array}$ & $\begin{array}{c}-0.029 \\
{[0.025]}\end{array}$ & $\begin{array}{c}-0.054 \\
{[0.027]+}\end{array}$ & $\begin{array}{c}-0.418 \\
{[0.455]}\end{array}$ & $\begin{array}{l}-0.839 \\
{[2.206]}\end{array}$ & $\begin{array}{c}0.307 \\
{[0.410]}\end{array}$ & $\begin{array}{l}-0.147 \\
{[1.004]}\end{array}$ \\
\hline ITT years $=2$ & $\begin{array}{c}0.016 \\
{[0.011]}\end{array}$ & $\begin{array}{c}0.013 \\
{[0.014]}\end{array}$ & $\begin{array}{c}0.161 \\
{[0.107]}\end{array}$ & $\begin{array}{l}-0.061 \\
{[0.041]}\end{array}$ & $\begin{array}{c}-0.089 \\
{[0.053]}\end{array}$ & $\begin{array}{c}1.118 \\
{[0.633]}\end{array}$ & $\begin{array}{c}-7.308 \\
{[3.090]^{*}}\end{array}$ & $\begin{array}{c}0.486 \\
{[0.545]}\end{array}$ & $\begin{array}{c}2.127 \\
{[0.897]^{*}}\end{array}$ \\
\hline ITT years $=3$ & $\begin{array}{l}0.015 \\
{[0.01]}\end{array}$ & $\begin{array}{c}0.012 \\
{[0.016]}\end{array}$ & $\begin{array}{l}-0.071 \\
{[0.073]}\end{array}$ & $\begin{array}{c}-0.088 \\
{[0.035]^{*}}\end{array}$ & $\begin{array}{l}-0.046 \\
{[0.042]}\end{array}$ & $\begin{array}{l}1.747 \\
{[1.231]}\end{array}$ & $\begin{array}{l}-3.406 \\
{[2.526]}\end{array}$ & $\begin{array}{c}0.117 \\
{[0.598]}\end{array}$ & $\begin{array}{c}0.439 \\
{[1.384]}\end{array}$ \\
\hline ITT years $=4+$ & $\begin{array}{c}0.014 \\
{[0.012]}\end{array}$ & $\begin{array}{c}0.018 \\
{[0.017]}\end{array}$ & $\begin{array}{c}-0.07 \\
{[0.067]}\end{array}$ & $\begin{array}{c}0.074 \\
{[0.037]}\end{array}$ & $\begin{array}{c}0.03 \\
{[0.052]}\end{array}$ & $\begin{array}{c}2.634 \\
{[1.017]^{*}}\end{array}$ & $\begin{array}{c}5.624 \\
{[2.953]}\end{array}$ & $\begin{array}{l}-0.101 \\
{[0.537]}\end{array}$ & $\begin{array}{l}-1.002 \\
{[1.935]}\end{array}$ \\
\hline School-Fixed Effects & YES & YES & YES & YES & YES & YES & YES & YES & YES \\
\hline Year-Fixed Effects & YES & YES & YES & YES & YES & YES & YES & YES & YES \\
\hline $\begin{array}{l}\text { Level of Observation } \\
\text { Observations }\end{array}$ & $\begin{array}{l}\text { student } \\
294288 \\
\end{array}$ & $\begin{array}{c}\text { school } \\
583 \\
\end{array}$ & $\begin{array}{c}\text { school } \\
531 \\
\end{array}$ & $\begin{array}{c}\text { school } \\
531 \\
\end{array}$ & $\begin{array}{c}\text { school } \\
531 \\
\end{array}$ & $\begin{array}{l}\text { school } \\
583\end{array}$ & $\begin{array}{c}\text { school } \\
583\end{array}$ & $\begin{array}{c}\text { school } \\
583 \\
\end{array}$ & $\begin{array}{c}\text { school } \\
583 \\
\end{array}$ \\
\hline
\end{tabular}

Heteroskedasticity robust standard errors in brackets are adjusted for clustering at the school level.

* significant at 5 percent; ** significant at 1 percent.. 
Table A5 Regression Estimates: Effect of APIP Program on Selected Student Characteristics by Adoption Cohort

\begin{tabular}{lcccccc}
\hline & 1 & 2 & 3 & 4 & 5 & 6 \\
\hline & $\begin{array}{c}\text { Math Score 10th } \\
\text { Grade }\end{array}$ & $\begin{array}{c}\text { Reading Score } \\
\text { 10th Grade }\end{array}$ & LEP & Low Income & Black & Hispanic \\
\cline { 2 - 7 } Adopted & -0.039 & -0.013 & 0.009 & -0.039 & 0.005 & -0.025 \\
ITT year>0 & {$[0.025]$} & {$[0.021]$} & {$[0.011]$} & {$[0.018]^{*}$} & {$[0.011]$} & {$[0.012]^{*}$} \\
\hline ITT year=1 & -0.02 & 0.013 & 0.009 & -0.021 & 0.003 & -0.014 \\
& {$[0.026]$} & {$[0.021]$} & {$[0.007]$} & {$[0.015]$} & {$[0.008]$} & {$[0.010]$} \\
ITT year=2 & $\mathbf{0 . 0 5 1}$ & -0.035 & 0.005 & $\mathbf{- 0 . 0 4 4}$ & 0.005 & $\mathbf{- 0 . 0 2 4}$ \\
& {$[\mathbf{0 . 0 3 2}+$} & {$[0.024]$} & {$[0.012]$} & {$[\mathbf{0 . 0 2 1}]^{*}$} & {$[0.011]$} & {$[\mathbf{0 . 0 1 3}]^{+}$} \\
ITT year=3 & -0.049 & -0.016 & 0.011 & $\mathbf{- 0 . 0 4 9}$ & 0.001 & $\mathbf{- 0 . 0 4}$ \\
& {$[0.034]$} & {$[0.030]$} & {$[0.016]$} & {$[\mathbf{0 . 0 2 4}]^{*}$} & {$[0.015]$} & {$[\mathbf{0 . 0 1 7}]^{*}$} \\
ITT year=4+ & -0.05 & -0.047 & 0.017 & $\mathbf{- 0 . 0 6 8}$ & 0.012 & $\mathbf{- 0 . 0 4 5}$ \\
& {$[0.033]$} & {$[0.29]$} & {$[0.022]$} & {$[\mathbf{0 . 0 3 0}]^{*}$} & {$[0.016]$} & {$[\mathbf{0 . 0 2 0}]^{*}$} \\
\multicolumn{1}{c}{ School FX } & YES & YES & YES & YES & YES & YES \\
Year FX & YES & YES & YES & YES & YES & YES \\
Observation & 290343 & 290343 & 290343 & 290343 & 290343 & 290343 \\
\hline
\end{tabular}

Heteroskedasticity robust standard errors in brackets are adjusted for clustering at the school level.

+ significant at 10 percent; * significant at 5 percent; ** significant at 1 percent.

All regressions control for tenth-grade test scores, ethnicity, gender, LEP status, and free or reduced lunch status.

Table A6 Regression Estimates: Effect of APIP Adoption Duration on the Timing of Sophomore Year Attendance

\begin{tabular}{|c|c|c|c|c|}
\hline & 1 & 2 & 3 & 4 \\
\hline & \multicolumn{4}{|c|}{ Sophomore within } \\
\hline & 2 years & 3 years & 4 years & 5 years \\
\hline \multirow{2}{*}{ ITT year=1 } & 0.011 & 0.011 & 0.016 & 0.017 \\
\hline & [0.008] & [0.009] & {$[0.009]+$} & {$[0.009]+$} \\
\hline \multirow{2}{*}{ ITT year=2 } & 0.02 & 0.021 & 0.023 & 0.024 \\
\hline & {$[0.010]+$} & {$[0.011]+$} & {$[0.011]^{*}$} & {$[0.011]^{*}$} \\
\hline \multirow{2}{*}{ ITT year=3 } & 0.036 & 0.042 & 0.049 & 0.052 \\
\hline & {$[0.010]^{* *}$} & {$[0.012]^{* *}$} & {$[0.012]^{* *}$} & {$[0.012]^{* *}$} \\
\hline \multirow{2}{*}{ ITT year $=4+$} & 0.051 & 0.053 & 0.057 & 0.058 \\
\hline & {$[0.013]^{* *}$} & {$[0.016]^{* *}$} & {$[0.016]^{* *}$} & {$[0.015]^{* *}$} \\
\hline Observations & 224971 & 224971 & 224971 & 224971 \\
\hline R-squared & 0.13 & 0.17 & 0.17 & 0.17 \\
\hline F: no effect & 0 & 0.01 & 0 & 0 \\
\hline
\end{tabular}

Robust standard errors in brackets are adjusted for clustering at the school level. + significant at 10 percent; * significant at 5 percent; ** significant at 1 percent 
Summary Means and Standard Deviations for Outcomes by Ethnicity

Read score 10th grade

Math score 10th grade

LEP

Low income

Female

Take any AP course

AP courses taken

Take any AP exams

AP exams taken

AP exams passed

Ever a freshman

Ever a sophomore

Ever a junior

Freshman GPA

Graduate with BA

Graduate with AA

Freshman at private college

Freshman at four-year college

Log wage in 2010 (4th quarter)

Wage in 2010 (4th quarter)

Working in 2010

Observations

\begin{tabular}{cc}
\multicolumn{2}{c}{ Black } \\
\hline Mean & Std. \\
\hline-0.257 & $(1.04)$ \\
-0.343 & $(0.97)$ \\
0.008 & $(0.09)$ \\
0.476 & $(0.50)$ \\
0.521 & $(0.50)$ \\
& \\
0.225 & $(0.42)$ \\
0.638 & $(1.52)$ \\
0.034 & $(0.18)$ \\
0.052 & $(0.33)$ \\
0.009 & $(0.13)$ \\
& \\
0.566 & $(0.69)$ \\
0.256 & $(0.52)$ \\
0.119 & $(0.33)$ \\
2.071 & $(1.20)$ \\
0.09 & $(0.29)$ \\
0.019 & $(0.14)$ \\
0.047 & $(0.21)$ \\
0.187 & $(0.40)$ \\
7.977 & $(1.37)$ \\
5180 & $(4762)$ \\
0.4771 & $(0.50)$ \\
\hline \multicolumn{2}{c}{69445}
\end{tabular}

69445

\begin{tabular}{cc}
\multicolumn{2}{c}{ Hispanic } \\
\hline Mean & Std. \\
\hline-0.203 & $(1.00)$ \\
-0.203 & $(0.95)$ \\
0.258 & $(0.44)$ \\
0.574 & $(0.49)$ \\
0.505 & $(0.50)$ \\
& \\
0.211 & $(0.41)$ \\
0.56 & $(1.42)$ \\
0.039 & $(0.19)$ \\
0.064 & $(0.39)$ \\
0.021 & $(0.19)$ \\
& \\
0.445 & $(0.62)$ \\
0.23 & $(0.49)$ \\
0.095 & $(0.30)$ \\
2.319 & $(1.19)$ \\
0.08 & $(0.27)$ \\
0.029 & $(0.17)$ \\
0.013 & $(0.11)$ \\
0.099 & $(0.30)$ \\
& \\
8.302 & $(1.18)$ \\
6252.8 & $(5081)$ \\
0.4631 & $(0.50)$ \\
\hline \multicolumn{2}{c}{128291}
\end{tabular}

\begin{tabular}{cc}
\multicolumn{2}{c}{ White } \\
\hline Mean & Std. \\
\hline 0.247 & $(0.90)$ \\
0.261 & $(0.94)$ \\
0.006 & $(0.08)$ \\
0.146 & $(0.35)$ \\
0.499 & $(0.50)$ \\
& \\
0.354 & $(0.48)$ \\
1.186 & $(2.11)$ \\
0.106 & $(0.31)$ \\
0.203 & $(0.76)$ \\
0.113 & $(0.54)$ \\
& \\
0.773 & $(0.72)$ \\
0.445 & $(0.63)$ \\
0.266 & $(0.45)$ \\
2.599 & $(1.13)$ \\
0.232 & $(0.42)$ \\
0.041 & $(0.20)$ \\
0.067 & $(0.25)$ \\
0.269 & $(0.45)$ \\
8.37 & $(1.32)$ \\
7608.67 & $(7947)$ \\
0.5229 & $(0.50)$ \\
\hline \multicolumn{2}{c}{83505} \\
\hline
\end{tabular}


Appendix Table A8: Changes in AP Course and Exam Takers after Adoption

\begin{tabular}{|c|c|c|c|c|c|c|c|c|c|c|}
\hline & 1 & 2 & 3 & 4 & 5 & 6 & 7 & 8 & 9 & 10 \\
\hline & \multicolumn{5}{|c|}{ AP Exam Takers } & \multicolumn{5}{|c|}{ AP Course Takers } \\
\hline & $\begin{array}{c}\text { School } \\
\text { Rank in } \\
\text { Tenth- } \\
\text { grade } \\
\text { Math }\end{array}$ & $\begin{array}{c}\text { School } \\
\text { Rank in } \\
\text { Tenth- } \\
\text { grade } \\
\text { Reading }\end{array}$ & $\begin{array}{l}\text { Normalized } \\
\text { Tenth-grade } \\
\text { Math Score }\end{array}$ & $\begin{array}{l}\text { Normalized } \\
\text { Tenth-grade } \\
\text { Reading } \\
\text { Score }\end{array}$ & $\begin{array}{c}\text { Predicted } \\
\text { GPA }\end{array}$ & $\begin{array}{c}\text { School } \\
\text { Rank in } \\
\text { Tenth- } \\
\text { grade } \\
\text { Math }\end{array}$ & $\begin{array}{c}\text { School } \\
\text { Rank in } \\
\text { Tenth- } \\
\text { grade } \\
\text { Reading }\end{array}$ & $\begin{array}{l}\text { Normalized } \\
\text { Tenth- } \\
\text { grade Math } \\
\text { Score }\end{array}$ & $\begin{array}{l}\text { Normalized } \\
\text { Tenth- } \\
\text { grade } \\
\text { Reading } \\
\text { Score }\end{array}$ & $\begin{array}{c}\text { Predicted } \\
\text { GPA }\end{array}$ \\
\hline ITT years $=1$ & $\begin{array}{c}-4.436 \\
{[7.667]}\end{array}$ & $\begin{array}{c}-1.304 \\
{[7.233]}\end{array}$ & $\begin{array}{c}0.013 \\
{[0.022]}\end{array}$ & $\begin{array}{c}0.02 \\
{[0.014]}\end{array}$ & $\begin{array}{c}0.017 \\
{[0.010]}\end{array}$ & $\begin{array}{l}-3.029 \\
{[7.558]}\end{array}$ & $\begin{array}{c}0.459 \\
{[7.099]}\end{array}$ & $\begin{array}{c}-0.015 \\
{[0.022]}\end{array}$ & $\begin{array}{c}0.005 \\
{[0.014]}\end{array}$ & $\begin{array}{c}-0.008 \\
{[0.007]}\end{array}$ \\
\hline ITT years $=2$ & $\begin{array}{c}-14.888 \\
{[9.446]}\end{array}$ & $\begin{array}{c}-6.259 \\
{[8.397]}\end{array}$ & $\begin{array}{c}0.012 \\
{[0.043]}\end{array}$ & $\begin{array}{c}0.002 \\
{[0.022]}\end{array}$ & $\begin{array}{c}0.011 \\
{[0.015]}\end{array}$ & $\begin{array}{c}-12.418 \\
{[10.529]}\end{array}$ & $\begin{array}{c}-7.98 \\
{[9.328]}\end{array}$ & $\begin{array}{c}-0.022 \\
{[0.043]}\end{array}$ & $\begin{array}{c}-0.003 \\
{[0.024]}\end{array}$ & $\begin{array}{c}-0.007 \\
{[0.012]}\end{array}$ \\
\hline ITT years $=3$ & $\begin{array}{c}-10.477 \\
{[8.673]}\end{array}$ & $\begin{array}{l}-5.166 \\
{[8.10]}\end{array}$ & $\begin{array}{l}-0.056 \\
{[0.05]}\end{array}$ & $\begin{array}{c}-0.015 \\
{[0.022]}\end{array}$ & $\begin{array}{c}0.001 \\
{[0.017]}\end{array}$ & $\begin{array}{c}-4.842 \\
{[10.27]}\end{array}$ & $\begin{array}{c}-0.799 \\
{[8.994]}\end{array}$ & $\begin{array}{c}-0.07 \\
{[0.051]}\end{array}$ & $\begin{array}{c}-0.033 \\
{[0.026]}\end{array}$ & $\begin{array}{c}-0.012 \\
{[0.014]}\end{array}$ \\
\hline ITT years $=4+$ & $\begin{array}{c}-7.994 \\
{[8.64]}\end{array}$ & $\begin{array}{c}-5.513 \\
{[8.773]}\end{array}$ & $\begin{array}{c}0.053 \\
{[0.058]}\end{array}$ & $\begin{array}{c}0.031 \\
{[0.028]}\end{array}$ & $\begin{array}{c}0.029 \\
{[0.019]}\end{array}$ & $\begin{array}{c}-1.859 \\
{[12.805]}\end{array}$ & $\begin{array}{c}-1.139 \\
{[11.867]}\end{array}$ & $\begin{array}{c}-0.002 \\
{[0.058]}\end{array}$ & $\begin{array}{c}-0.011 \\
{[0.031]}\end{array}$ & $\begin{array}{c}0.008 \\
{[0.016]}\end{array}$ \\
\hline School FX & YES & YES & YES & YES & YES & YES & YES & YES & YES & YES \\
\hline Year FX & YES & YES & YES & YES & YES & YES & YES & YES & YES & YES \\
\hline Observations & 18008 & 18008 & 18008 & 18008 & 18008 & 61855 & 61855 & 61855 & 61855 & 61855 \\
\hline
\end{tabular}

Heteroskedasticity robust standard errors in brackets are adjusted for clustering at the school level.

* significant at 5 percent; ** significant at 1 percent.

Table A9 APIP Effect on Medium-run Outcomes

\begin{tabular}{ccccccc}
\hline Ever a & Freshman-year & Ever a & Ever a & Total & Any & Degree within \\
freshman & GPA & sophomore & Junior & Credits & degree & 4 years
\end{tabular}

\begin{tabular}{lccccccc} 
& \multicolumn{7}{c}{ Expected High School Graduation Before 2005 } \\
\cline { 2 - 7 } Adopted & $\mathbf{0 . 0 4 2}$ & $\mathbf{0 . 0 4}$ & $\mathbf{0 . 0 4 3}$ & $\mathbf{0 . 0 2}$ & $\mathbf{7 . 4 9 7}$ & 0.004 & 0.002 \\
& {$[\mathbf{0 . 0 1 4}]^{*}$} & {$[\mathbf{0 . 0 1 7}]^{*}$} & {$[\mathbf{0 . 0 1 0}]^{* *}$} & {$[\mathbf{0 . 0 0 7}]^{* *}$} & {$[\mathbf{1 . 9 2 3}]^{* *}$} & {$[0.011]$} & {$[0.003]$} \\
\hline ITT year= 1 & $\mathbf{0 . 0 3 3}$ & 0.009 & $\mathbf{0 . 0 2 7}$ & $\mathbf{0 . 0 1 6}$ & $\mathbf{4 . 3 9 5}$ & 0.005 & 0.002 \\
& {$[\mathbf{0 . 0 1 7}]^{+}$} & {$[0.020]$} & {$[\mathbf{0 . 0 1 0}]^{*}$} & {$[\mathbf{0 . 0 0 6}]^{* *}$} & {$[\mathbf{1 . 8 4 3}]^{*}$} & {$[0.006]$} & {$[0.003]$} \\
ITT year= 2 & $\mathbf{0 . 0 5 3}$ & $\mathbf{0 . 0 4 6}$ & $\mathbf{0 . 0 3 3}$ & $\mathbf{0 . 0 1 9}$ & $\mathbf{6 . 6 2 6}$ & 0.003 & 0.000 \\
& {$[\mathbf{0 . 0 1 7}]^{* *}$} & {$[\mathbf{0 . 0 2 6}]^{*}$} & {$[\mathbf{0 . 0 1 0}]^{* *}$} & {$[\mathbf{0 . 0 0 7}]^{* *}$} & {$[\mathbf{1 . 7 0 8}]^{* *}$} & {$[0.009]$} & {$[0.004]$} \\
ITT year= 3 & $\mathbf{0 . 0 6 5}$ & $\mathbf{0 . 0 4 8}$ & $\mathbf{0 . 0 6 1}$ & $\mathbf{0 . 0 2 2}$ & $\mathbf{9 . 3 6 8}$ & 0.005 & 0.000 \\
& {$[\mathbf{0 . 0 1 9}]^{* *}$} & {$[\mathbf{0 . 0 2 9}]^{*}$} & {$[\mathbf{0 . 0 1 3}]^{* *}$} & {$[\mathbf{0 . 0 0 9}]^{*}$} & {$[\mathbf{2 . 2 0 5}]^{* *}$} & {$[0.012]$} & {$[0.004]$} \\
ITT year= 4+ & $\mathbf{0 . 0 4}$ & $\mathbf{0 . 0 6 6}$ & $\mathbf{0 . 0 6 5}$ & 0.013 & $\mathbf{4 . 1 8 5}$ & 0.018 & $\mathbf{0 . 0 1}$ \\
& {$[\mathbf{0 . 0 2 3}]^{+}$} & {$[\mathbf{0 . 0 2 9}]^{*}$} & {$[\mathbf{0 . 0 1 6}]^{* *}$} & {$[0.011]$} & {$[\mathbf{2 . 4 1 3}]^{+}$} & {$[0.016]$} & {$[\mathbf{0 . 0 0 6}]^{+}$} \\
& & & & & & & \\
School FX & YES & YES & YES & YES & YES & YES & YES \\
Year FX & YES & YES & YES & YES & YES & YES & YES \\
Observations & 224971 & 93286 & 224971 & 224971 & 224971 & 224971 & 224971 \\
\hline
\end{tabular}

Heteroskedasticity robust standard errors in brackets are adjusted for clustering at the school level. + significant at 10 percent; * significant at 5 percent; ** significant at 1 percent.

All regressions control for tenth-grade test scores, gender, ethnicity, LEP status, and free or reduced lunch Heteroskedasticity robust standard errors in brackets are adjusted for clustering at the school level. 


\section{Appendix Note 1: Relationships with Donors}

Given that APIP adoption was not random, readers may worry that schools could self-select into the APIP. Because the analytical sample includes only those schools that may have selected into the program and all analyses are based on within-school variation, this type of self-selection will not bias the results, as long as there are no changes in schools that coincide with the exact timing of APIP adoption (which is about two years after when selection would take place). In any case, it is important to ascertain the extent to which schools may have selected into the APIP. One natural question to ask is whether the APIP donors had previous contact with the schools. If so, it would imply that the APIP schools are those types of schools with relationships with donor organizations. However, it does not imply that the timing of adoption is endogenous to changes within schools. Of the schools that were treated in the sample, seven had donors for which there were previous projects. ${ }^{37}$ However, none of these schools had any coincident projects that would confound the APIP effects. To ensure that the results are not driven by these schools, I ran the main models excluding these schools, and the results remain unchanged. Of the comparison APIP schools (i.e., those APIP schools that have not yet adopted the program), seven of the Austin schools had relationships with the Michael and Susan Dell Foundation. These seven Austin schools adopted the APIP in 2008, so they serve as comparison schools in my data. However, starting in 2002, these schools all had the Advancement Via Individual Determination (AVID) program, Project Advance, and Project Smart. All of these programs are collegereadiness programs that would lead to an underestimate of the APIP's effects (because these schools serve as comparison schools rather than as treatment schools in these data). Again, I have determined that the results are robust to excluding these seven schools.

Another important related question is whether any of the donors were involved in other concurrent projects in schools that would confound the APIP effect. While the answer for most school is no, there is one potentially problematic donor relationship that requires some discussion. In five of the Dallas schools that started the program in $2003,{ }^{38}$ the donor offered scholarships to any student who was accepted to college. As such, for these schools, the APIP effect is potentially confounded with a financial aid effect. To ensure that these five schools do not drive the main results, I have replicated the analysis without these five schools, and the treatment effects are slightly larger with these school excluded. As such, I can rule out that the few potentially problematic donor relationships bias the results.

\section{Appendix Note 2: Related Statewide Policies During the Sample Period}

The Texas ten percent rule was put in place in 1997 and ensured that the top ten percent of students from each high school in the state would be guaranteed admission to a Texas public university. One would expect college matriculation rates to have increased in schools that have on average low achievement, such as the selected APIP schools, even if these schools did not adopt the APIP. However, none of the APIP schools adopted the APIP in 1997, so that the timing of adoption is not coincident with the introduction of the new state policy. Furthermore, all the main results are robust to using only those schools that adopted the APIP after 2000.

The Texas statewide Advanced Placement Incentive Program was introduced in academic year 1999-2000. Under this statewide program, the state appropriated \$21 million over the years 1998-2000 for the Texas APIP, up from \$3 million the previous biennium. The statewide program provides a \$30 reduction in exam fees for all public school students who are approved to take AP exams, teacher training grants of up to $\$ 450$, up to $\$ 3,000$ in equipment and material grants for AP classes, and financial incentives to the schools of up to $\$ 100$ for each student who scores 3 or better on any AP exam. One would expect this policy to increase AP participation and effort, even if the selected APIP schools did not in fact adopt the program. However, all the estimated effects exceed those of the statewide program. (Source: Texas Education Agency Press Release: "Number of Advanced Placement Exams Taken by Texas Students Increases Dramatically.” August 23, 2000).

\footnotetext{
${ }^{37}$ Dodge Jones Foundation in Abilene (2 in 2003); Perkins Prothro Foundation in Wichita Falls (3 in 2002); Munson Foundation in Denison (1 in 2004); and Fourth Partner Foundation in Tyler (2 in 2002).

${ }^{38}$ Kimball, Roosevelt, Sunset, Thomas Jefferson, and Seagoville High Schools.
} 